\title{
ILLUSTRATED KEYS TO THE GENERA OF MOSQUITOES (DIPTERA: CULICWAE) IN SRI LANKA
}

\author{
F.P. AMERASINGHE \\ Department of Zoology, University of Peradeniya, Peradeniya.
}

(Received: 01 May 1995; accepted: 11 August 1995)

\begin{abstract}
Illustrated keys are provided for the identification of the adults, pupae and fourth stage larvae of 17 genera of mosquitoes (Diptera: Culicidae) occurring in Sri Lanka. The genera included are Aedeomyia Theobald, Aedes Meigen, Anopheles Meigen, Armigeres Theobald, Coquillettidia Dyar, Culex Linnaeus, Ficalbia Theobald, Heizmannia Ludlow, Hodgesia Theobald, Malaya Leicester, Mansonia Blanchard, Mimomyia Theobald, Orthopodomyia Theobald, Topomyia Leicester, Toxorhynchites Theobald, Tripteroides Giles, and Uranotaenia Lynch Arribalzaga. Genus Topomyia is listed for the first time from Sri Lanka, based on as-yet undescribed material deposited in the collections of the Natural History Museum, Wạshington DC., USA.
\end{abstract}

Key words: Adults, generic keys, larvae, mosquitoes, pupae, Sri Lanka.

\section{IN'TRODUCTION}

Mosquitoes are a group of nematocerous Diptera that are of medical or veterinary importance because many species are involved in the transmission of human and animal diseases. A total of 141 species belonging to 16 genera are currently listed from Sri Lanka. ${ }^{1,2}$ The majority of these species are harmless to humans and livestock, but several have been implicated in the transmission of diseases such as malaria, dengue, bancroftian and brugian filariasis, Japanese encephalitis, dirofilariasis, and setariasis in the country. In addition, some mosquito-transmitted arboviruses that are potentially encephalitogenic, and others of unknown aetiology occur on the island, ${ }^{3}$ and their local vectors are not known. The taxonomy of Sri Lankan mosquitoes is, therefore, a subject of some importance.

There have been a few attempts to develop keys and descriptions for the identification of Sri Lankan mosquitoes by workers such as Carter, ${ }^{4,5}$ SeniorWhite, ${ }^{6}$ and Carter \& Wijesundara. ${ }^{7}$ All of these date to the first half of this century, and are of limited scope, dealing with one or more life stages of species in a limited number of genera. In the main, regional or other country keys such as those published by Edwards, ${ }^{8}$ Christophers, ${ }^{9}$ Barraud, ${ }^{10}$ Thurman ${ }^{11}$ and Reid $^{12}$ have been used for the identification of local mosquitoes. More recently, a thorough revision of the Oriental and Southeast Asian fauna, contained in a large number of publications by specialists in different mosquito genera, was done as a result of the Southeast Asia Mosquito Project (SEAMP) and Medical Entomology Project (MEP) of the Smithsonian Institution during 1965-1985. These taxonomic works are not readily accessible to local workers. Moreover, being regional in scope, they often include species or groups of species not represented in the island, making them somewhat inconvenient to the average user who is not a specialist taxonomist, but desires to identify local genera or 
species in the course of surveillance and control operations, or for research. There is thus a need for modern taxonomic keys to identify local mosquitoes to be made available to medical entomologists working in Sri Lanka.

As part of ongoing studies on the taxonomy of local mosquitoes, the present author has published keys for the identification of adult and larval anopheline mosquitoes, ${ }^{13,14}$ and keys to anopheline pupae. ${ }^{15}$ The scope of these studies has now been widened to include other genera that contain representatives of medical or veterinary importance and, eventually, to cover the entire known local fauna. Since at least 16 genera occur in the island (a species of an additional genus, Topomyia, occurs ${ }^{16}$ but has not yet been formally reported in the literature), it is thought desirable at this stage to publish keys for the identification of the major life stages (i.e., adults, pupae, fourth stage larvae) of these genera.

\section{METHODS AND MATERIALS}

The genera included in this work are Aedeomyia Theobald, Aedes Meigen, Anopheles Meigen, Armigeres Theobald, Coquillettidia Dyar, Culex Linnaeus, Ficalbia Theobald, Heizmannia Ludlow, Hodgesia Theobald, Malaya Leicester, Mansonia Blanchard, Mimomyia Theobald, Orthopodomyia Theobald, Topomyia Leicester, Toxorhynchites Theobald, Tripteroides Giles, and Uranotaenia Lynch Arribalzaga. The inclusion of Topomyia is based on the reported collection during the Smithsonian Institutions' Medical Entomology Project in 1975, of an as-yet undescribed species of the genus from the Kalatuwawa area. ${ }^{18}$ This material is deposited in the collections of the Natural History Museum, Washington DC., USA. It is thought desirable to include this in the key because local workers who may encounter species of the genus will otherwise have difficulty in genericlevel identification:

Recently published keys to mosquito genera ${ }^{17-20}$ were used as the basic literature sources to formulate the present key. Key characters and key steps were modified so as to be consistent with the characteristics of the local species representing the different genera. This was evaluated on the basis of both a survey of published taxonomic works relating to the local species, as well as by the direct examination of adult, pupal and larval material from reference material available at the Department of Zoology, University of Peradeniya. The illustrations were drawn by the author, and are semi-diagrammatic representations of characters used in the keys, to assist those unfamiliar with the morphology and chaetotaxy of mosquito adult and immature stages. They follow the standard conventions established for mosquito taxonomic publications. ${ }^{21}$

In several instances where only a single species of a genus is represented on the island, generic characters used in the keys are sufficient to identify the species. These cases are: Aedeomyia (only Ad. catasticta Knab), Coquillettidia (only Cq. crassipes [van der Wulp]), Ficalbia (only Fi. minima [Theobald]), and Malaya (only $M l$. genurostris Leicester). 
Brief notes are provided at the end of each key where comment on the characters used is felt to be necessary. It needs to be emphasized that taxonomic keys are only a rapid and convenient guide to identification, based on the examination of a few important characters at each step. In cases of doubt, it will be necessary for workers to consult published literature with detailed descriptions of generic characters, or refer the specimens to a recognized taxonomist or Museum for confirmation of identification.

\section{KEYS TO THE GENERA OF SRI LANKA MOSQUITOES (A) KEY TO ADULTS}

1. Proboscis long, recurved; posterior margin of wing emarginate just beyond tip of vein $\mathrm{CuA}$ (Fig 1a) ................... Toxorhynchites

Proboscis straight or only slightly curved; posterior margin of wing evenly rounded or only slightly emarginated (Fig. 1b)

2(1). Scutellum evenly rounded, with evenly distributed setae; female maxillary palp almost as long as proboscis (Fig. 2a), male palp long, apex expanded to form a club; abdominal segments with only occasional scales Anopheles

Scutellum trilobed, with setae in 3 groups; female maxillary palp markedly shorter than proboscis (Fig. 2b), male palp variable in length, not clubbed at apex (except in some Mimomyia); abdominal segments densely covered by scales 3

3(2). Mid- and hindfemora with large sub-erect apical scale tufts; female antennal flagellomeres short and thick, basal flagellomere with prominent scale tuft; male antenna with the two terminal flagellomeres markedly thickened (Fig. 3a) Aedeomyia catasticta

Femora and antenna otherwise (Fig 3b) 4

4(3). Fore- and midtarsomere 1 distinctly longer than other four tarsomeres combined, tarsomere 4 of fore- and midlegs short, about as long as wide; wing spotted, as in many species of Anopheles. (Fig. 4a) Orthopodomyia

Fore- and midtarsomere 1 shorter than other four tarsomeres combined, tarsomere 4 of fore- and midlegs much longer than wide; wing variable (Fig. 4 b)

5(4). Prespiracular area with setae or covered with scales

(Fig. 5a)

Prespiracular area bare (Fig. 5b) 
6(5). Scutum with conspicuous median longitudinal double line of broad scales, usually white or silver; other scutal scales narrow (Fig. 6a)

Scutum without median longitudinal double line of broad pale or dark scales; broad or narrow pale scales may be present along scutal margin (fig. 6b)

7(6). Proboscis swollen apically, upturned and with long apical setae (Fig. 7a) Malaya genurostris

Proboscis slender, if at all only with slightly swollen labellum at tip, not upturned or with long apical setae (Fig. 7b) Topomyia

8(6). Cell $R 2$ of wing always shorter than vein $R 2+3$; vein $1 A$ reaching wing margin before, or at most very slightly beyond base of vein $\mathrm{mcu}$ (Fig 8a) Uranotaenia

Cell $R 2$ at least as long as vein $R 2+3$; vein $1 A$ reaching wing margin well beyond base of vein $\mathrm{mcu}$ (Fig. $8 \mathrm{~b}$ ) Tripteroides

9(5). Mesopostnotum with setae; scutum with broad metallic decumbent scales (Fig. 9a)

Heizmannia

Mesopostnotum without setae; scutum with narrow scales (Fig. 9b)

10(9). Outstanding scales on outer half of wing with emarginate tips; vein $1 A$ reaching wing margin before, or at most, very slightly beyond base of vein $\mathrm{mcu}$ (Fig. 10a) Hodgesia

Outstanding scales on outer half of wing without emarginate tips; vein $1 A$ reaching wing margin well beyond base of vein $\mathrm{mcu}$ (Fig. 10b), except Aedes subgenus Cancraedes

11(10). Postspiracular setae present (Fig. 11a) (note presence of alveoli if setae missing)

Postspiracular setae absent (Fig. 11b) or obscured by heavy scalation

12(11). Dorsal surface of wing with broad, asymmetrical dark and pale scales intermixed (Fig. 12a)

Dorsal surface of wing with narrow scales, if broad, then not asymmetrical (Fig. 12b) 
13(12). Proboscis rather stout, laterally compressed and curved downwards; occiput with broad decumbent scales (Fig. 13a) Armigeres subgenus Armigeres

Proboscis more slender, not laterally compressed or notably curved; occiput with at least some decumbent scales narrow (except in subgenus Stegomyia) (Fig. 13b) (in part) Aedes

14(11). Alula bare or with broad flat decumbent scales

(Fig. 14a) Mimomyia

Alula fringed with narrow scales or moderately broad erect scales (Fig. 14b) 15

15(14). Postspiracular area covered with broad scales

(Fig. 15a)

Postspiracular area without scales (Fig. 15b) 17

16(15). Postspiracular area dark scaled dorsally and white scaled ventrally; female palpus $0.4-0.7$ length of proboscis (Fig. 16a) ......................Armigeres subgenus Leicesteria

Postspiracular area with pale scales only; female palpus less than 0.4 length of proboscis (Fig. 16b) .............. (in part) Aedes

17(15). Female antenna with flagellomere 1 approx. three times the length of flagellomere 2; male proboscis greatly swollen on distal third or more; palpus very short, seldom longer than clypeus (Fig. 17a) Ficalbia minima

Female antenna with flagellomere 1 approx. equal length of flagellomere 2; male proboscis only slightly swollen apically; palpus longer than clypeus (Fig. 17b)

18(17). Pulvilli absent; tarsal claws prominent on all legs; abdominal terga with purple metallic scales; wing with yellow scales (Fig. 18a) Coquillettidia crassipes

Pulvilli well developed at least on hindleg; tarsal claws usually small, inconspicuous; abdominal terga and wing scales otherwise (Fig. 18b) Culex

NOTE: Key step 11 -Postspiracular setae are present on all Sri Lankan Aedes, but may be obscured by scales that may also be present on this area (e.g., in some species of subgenus Stegomyia); thus characters for separating Aedes from both branches of this step are included in the key. 


\section{(B) KEY TO PUPAE}

1. Seta 1-X present; seta 9-VIII reduced; paddle without apical seta (Fig. 19a)

Seta $1-X$ absent; seta $9-$ VIII and paddle various (Fig. 19b)

2(1). Seta 9-IV-VII distinct stout spine arising at or near posterolateral angle of segment (Fig. 20a)

Seta $9-I V-V I I$ small, usually weak, if stout, then not arising at or near postero-lateral angle of segment (Fig. 20b)

3(2). Paddle smooth on both margins, deeply cleft at apex; seta $1-P a$ at least half as long as paddle; seta $5-I V-V I$ with long aciculate median branch and short lateral branches (Fig. 21a)

Aedeomyia catasticta

Paddle with distinct fine fringe, spicules or teeth on at least lateral margin, not cleft at apex; seta 1-Pa various; seta $5-I V-V I$ single or branched, but without long aciculate median branch (Fig. $2 \mathrm{lb}$ ) ............................................ Anopheles

4(2). Trumpets modified for insertion into aquatic plant tissue (Fig. 22a)

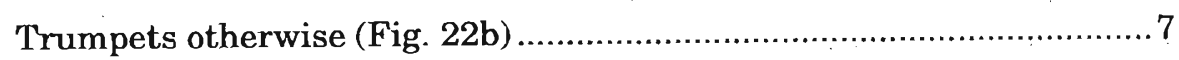

5(4). Seta 1-I single or bifid (Fig. 23a)

Seta 1 - $I$ with more than 4 branches (Fig. 23b) (in part) Mimomyia

6(5). Some abdominal setae well developed; trumpet with strongly sclerotized spine-like process at apex (Fig. 24a) Mansonia

All abdominal setae minute; trumpet with less strongly developed spine-like process at apex (Fig. 24b) Coquillettidia crassipes

7(4). Trumpet with long, narrow tragus from near base

(Fig. 25a) Hodgesia

Trumpet without tragus (Fig. 25b) 8 
8(7). Setae 1,2-Pa absent; paddles small, usually with pointed apex

(Fig. 26a)

At least Seta 1-Pa present; if absent, then paddles never small or with pointed apex (Fig. 26b)

9(8). Trumpet subcylindrical, inner and outer walls widely separated (Fig. 27a)

Trumpet subconical, or with inner and outer walls closely apposed or both (Fig. $27 \mathrm{~b}$ ) Tripteroides

10(9). Seta 6-VII relatively well developed, arising cephalad of seta 9-VII (Fig. 28a) Malaya genurostris

Seta.6-VII usually less well developed, arising close to and laterad of seta $9-V I I$ (Fig. 28b) Topomyia

11(8). Paddle with inner half deeply excavated near base, usually much broader than outer half; seta 9-IX usually. present (Fig. 29a) Uranotaenia

Paddle otherwise; seta 9-IX absent (Fig. 29b) 12

12(11). Paddle margins with long delicate fringe (Fig. 30a)

Paddle margins smooth, serrated, or with short spicules (Fig. 30b)

13(12). Seta $6-V I$ very strongly developed, longer and much stouter than 5-VI (Fig. 31a) Armigeres

Seta 6 -VI otherwise (Fig. $31 \mathrm{~b}$ ) 14

14(13). Seta 9-VI minute, smaller than other setae on segment (Fig. 32a) Heizmannia

Seta 9-VI larger than or equal in size to at least some setae on segment (Fig. 32b) (in part) Aedes

15(12). Paddle margins strongly serrate (Fig. 33a) 16

Paddle margins smooth or with short spicules (Fig. 33b) 17 
16(15). Paddle serrate on outer margin only; trumpet less than 10 times as long as width (Fig. 34a) Ficalbia minima

Paddle serrate on both margins; trumpet long, at least 10 times as long as width (Fig. 34b) (in part) Mimomyia

17(15). Trumpet with well developed sub-basal tracheation; seta $2-P a$ present in addition to $1-P a$; paddle margin smooth (Fig. 35a). Culex

Trumpet with rudimentary sub-basal tracheation; seta 2-Pa absent; paddle margin smooth or with short spicules (Fig. 35b) 18

18(17). Seta 8-C arising level with or slightly posterior to base of trumpet, nearly level with 9-C; seta 9-VII-VIII long, stout, plumose, 9-VIII half or more the length of the paddle; paddle more or less rectangular with thickened basal part on outer edge, paddle margin smooth; seta 1.Pa small (Fig. 36a) Orthopodomyia

Seta 8-C arising anterior to or at most slightly posterior to base of trumpet, very much anterior to $9-C$; seta $9-V I I-V I I I$, or paddle shape, or paddle margin, or seta $1-P a$ (or all these characters) otherwise (Fig. 36b) Aedes

NOTES: Key step 5 - Mimomyia hybrida will key out here; other species of the genus will key out to step 15.

Key step 14 - Aedes with long paddle fringe spicules (primarily subgenus Stegomyia, excepting Ae. aegypti) will key out here. Others will key out to step 18 .

Key step 17 - Seta 2-Pa is present on all known Sri Lankan representatives of the subgenera Culex, Culiciomyia, Lophoceraomyia, and Lutzia. In subgenus Eumelanomyia, only the pupae of $C x$. brevipalpis (seta 1-Pa absent, 2-Pa present), $C x$. malayi and $C x$. pluvialis (both seta 1,2-Pa present) are known; those of $C x$. castrensis and $C x$. campilunati are unknown. Thus for the present, the occurrence of seta 2-Pa can be considered diagnostic for Sri Lankan Culex.

Key steps $17 \& 18$ - Mattingly ${ }^{17}$ and Rattanarithiku ${ }^{18}$ use the relative positions of seta $8,9-C$ to separate genus $C$ ulex (8-C arising nearly level with 9-C) from Aedes (8-C distinctly anterior to 9-C). However, this is not a good character since the latter condition (8-C markedly anterior to $9-C$ ) is seen in many Sri Lanka species of Culex, for example, in the subgenera Culex and Lophoceraomyia. The above two authors also separate Culex and Aedes on the basis of seta 9-VII being 
located cephalad of the posterolateral corner of segment VII in Culex, and at the posterolateral corner in Aedes. This too, does not hold true for many Sri Lankan Aedes, especially species of the subgenus Aedimorphus.

Key step 18 - Genus Orthopodomyia is defined on the basis of a combination of 4 characters, which serve to separate it from Aedes, since no single character is diagnostic. Resemblances in characters between Orthopodomyia and the eleven subgenera of Sri Lankan Aedes can be resolved as follows: (1) Subgenus Verrallina has seta 9. $V I I-V I I I$ weak and 1-6 branched (these seta large, multi-branched and plumose in Orthopodomyia); (2) Subgenus Aedimorphus has seta 9.VII-VIII moderately large and 2-14 branched, but seta 9 -VIII is less than half the length of the paddle (equal to or greater than this length in Orthopodomyia); (3) Subgenus Stegomyia in Sri Lanka has the paddle with distinct, often very long, fringe spicules and seta 1-Pa long and single or multibranched (smooth paddle margins and very short, single seta 1-Pa in Orthopodomyia); (4) Subgenus Cancraedes (Ae. simplex Theobald only) has fringe spicules on both paddle margins and a long seta 1-Pa (smooth paddle margins and very short seta $1-\mathrm{Pa}$ in Orthopodomyia); (5) Subgenus Neomelanoconion (Ae. lineatopennis [Ludlow] only), has seta 9-VII-VIII multibranched but extremely small, and the paddle with small marginal spicules (large, multibranched, plumose seta 9.VII-VIII and smooth paddle margin in Orthopodomyia); (6) Subgenus Diceromyia has setae 9.VII single, 9-VIII 2-3 branched, and 1-Pa long (seta 9-VII-VIII multibranched and plumose, seta 1 -Pa very short in Orthopodomyia); (7) Subgenus Christophersiomyia has seta $1-P a$ extremely long (very short in Orthopodomyia); (8) Subgenus Rhinoskusea has seta 9-VII multibranched but small, and seta 1-Pa long and 3-6 branched (seta 9 -VII multibranched but large, seta $1-P a$ single, very short in Orthopodomyia); (9) Subgenus Paraedes has setae 9-VII long and 1-3 branched, 9-VIII long and single, and 1-Pa long (setae 9-VII-VIII large and multibranched, 1.Pa very short in Orthopodomyia); (10) Subgenus Mucidus has seta 9-VII-VIII multibranched and small, with 9-VIII less than half the length of the paddle, and seta 1-Pa short but generally 2-branched (seta $9 \cdot V I I \cdot V I I I$ multibranched and large, 9-VIII equal to or greater than half the length of the paddle, and 1-Pa short but single in Orthopodomyia); (11) Subgenus Finlaya of Aedes in the Oriental region has not been revised in its entirety to-date and as such, generalizations regarding pupal characters have to be regarded as provisional. However, species of the subgenus have the origin of seta 8-C distinctly anterior to $9-C$ unlike Orthopodomyia where the two setae are nearly level. Also, Finlaya in general possess a rounded paddle with a long seta 1-Pa compared to the angular shape with a very short seta $1-P a$ that is characteristic of Orthopodomyia. 


\section{(C) KEY TO LARVAE}

1. Siphon absent; seta 1 palmate on most abdominal terga (Fig. 37a). Anopheles

Siphon present; seta 1 not palmate on abdominal terga (Fig. 37b)

2(1). Siphon short, attenuated, with saw-toothed process near apex. adapted for piercing plant tissue (Fig. 38a).

Siphon cylindrical in shape, if attenuated apically then without saw-toothed process (Fig. 38b)

3(2). Antenna with part distal to setae 2,3-A as long as or longer than proximal part; saddle with at most 2 weak setae ventrally (Fig. 39a) .Coquillettidia crassipes

Antenna with part distal to setae 2,3-A less than 0.5 as long as proximal part; saddle with $3-4$ robust setae ventrally (Fig. 39b) Mansonia

4(2). Ventral brush (4-X) with 1-2 pairs of setae (Fig. 40a)

Ventral brush (4-X) with 4 or more pairs of fan-like setae (Fig. 40b) .7

5(4). Seta 5 or $6-P$ usually single, not stellate; 6 - $M$ or $7-T$ usually stout spine; comb scales usually in single row (Fig. 41a) Tripteroides

Setae 5 and $6-P$ large, stellate; $6-M$ and $7-T$ never stout or spine-like; comb scales usually in 2 or more rows (Fig. 41b)

6(5). Abdominal segments IV-VI with stellate setae or maxillary palpus well developed or siphon index at least 6.0 (Fig. 42a)

Topomyia

Abdominal segments IV-VI without stellate setae; maxillary palpus undeveloped; siphon index at most 4.0

(Fig. 42b)

Malaya genurostris

7(4). Antenna enlarged, markedly curved and flattened; siphon with paired hooks and branched setae at tip (Fig. 43a) Aedeomyia catasticta 
8(7). Siphon with 3 or more pairs of setae 1-S

(Fig. 44a) Culex

Siphon with 1 pair of setae $1-S$ (Fig. 44b) ............................ 9

9(8). Siphon without pecten (Fig. 45a) .................................. 10

Siphon with pecten (Fig. 45b) ........................................ 13

10(9). Lateral palatal brush with 6-10 curved, stout rods; comb scales absent (Fig. 46a) Toxorhynchites

Lateral palatal brush with numerous fine, simple or pectinate filaments; comb scales present (Fig. 46b)

11(10). Distal part of antenna with joint, apical part freely. movable; setae 2,3-A attached at joint (Fig. 47a) Mimomyia subgenus Etorleptiomyia

Distal part of antenna without joint; setae 2,3-A attached apically or sub-apically (Fig. 47b)

12(11). Abdominal segment VIII with a dorsal sclerotized plate, sometimes also present on segment VII; seta 1-A large, with 4 or more branches (Fig. 48a) Orthopodomyia

Abdominal segments VII and VIII without sclerotized plates; seta 1 - $A$ minute, usually single or bifid (Fig. $48 \mathrm{~b}$ ) Armigeres

13(9). Seta 1-S attached near siphon base (Fig. 49a) 14

Seta 1-S attached beyond basal 0.33 of siphon (Fig. 49b).

14(13). Seta $1-C$ simple; pecten with at least 3 teeth, usually more (Fig. 50a) Hodgesia

Seta 1-C strongly barbed; pecten with at most 2 teeth (Fig. 50b). Ficalbia minima

15(13). Distal part of antenna with joint, apical part freely movable; setae 2,3-A attached at joint (Fig. 47a) Mimomyia subgenus Mimomyia

Distal part of antenna without joint; setae 2,3- $A$ attached apically or sub-apically (Fig. 47b) 
16(15). Venter of head with hypostomal suture absent or incomplete, not reaching the posterior tentorial pit; comb scales usually attached to comb plate; seta 5 and/or $6-C$ often spine-like; (Fig. 51a) Uranotaenia

Venter of head with well developed hypostomal suture extending from level of mentum to posterior tentorial pit; comb scales not borne on comb plate; setae 5,6 - $C$ not spine-like; (Fig. 51b)

17(16). Seta 4- $C$ large, multibranched, subequal in size to $7-C$; 6-C with two unequal branches (Fig. 52a), rarely single

Heizmannia

Seta 4- $C$ small, variously branched, less than 0.5 length of 7-C; if 4-C longer, 6-C never with two unequal branches or head sub-quadrate (Mucidus) or seta $4-C$ closer to $6-C$ than to 5-C (Stegomyia) (Fig. 52b) Aedes

NOTE: Key step 16 - The absence or only partial development of a hypostomal suture is absolutely diagnostic for genus Uranotaenia, and separates it from all other genera. ${ }^{17}$

Figures 1-52 are semi-diagrammatic representations of key characters. Abbreviations used in the illustrations are as follows:

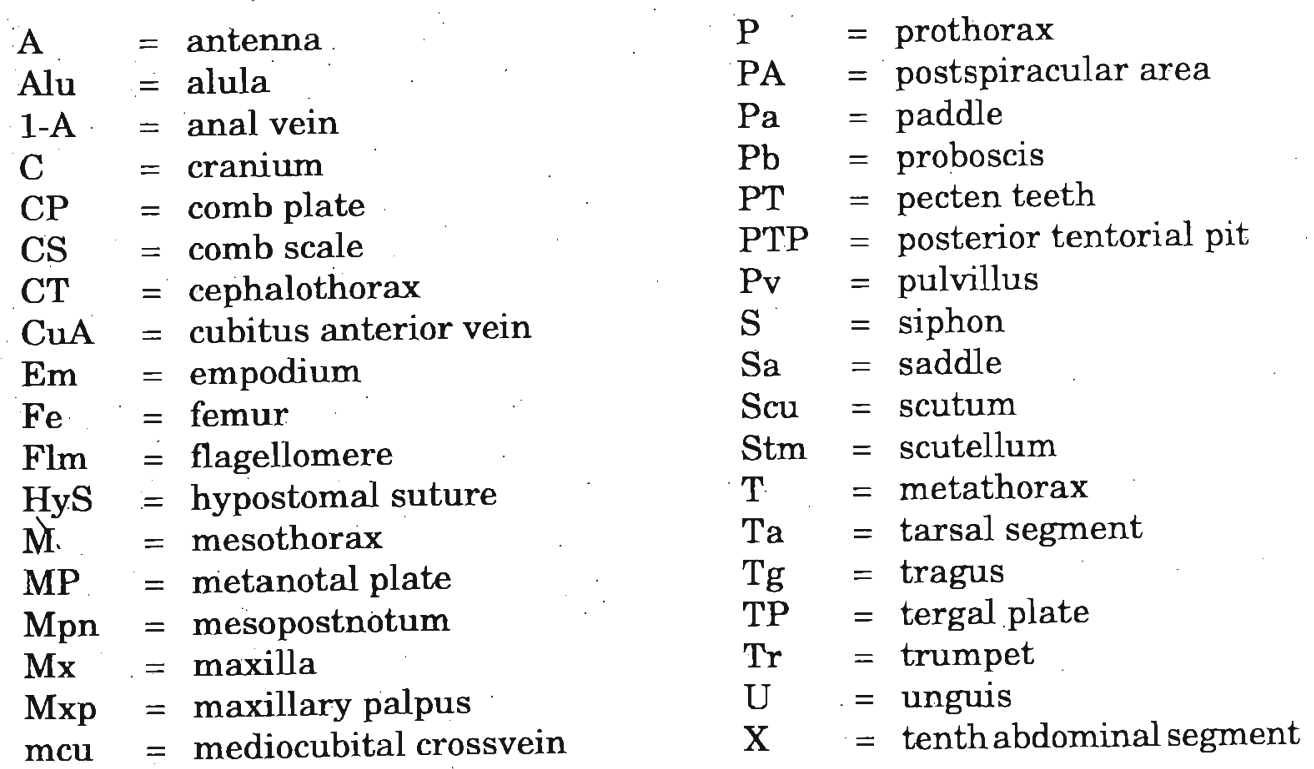



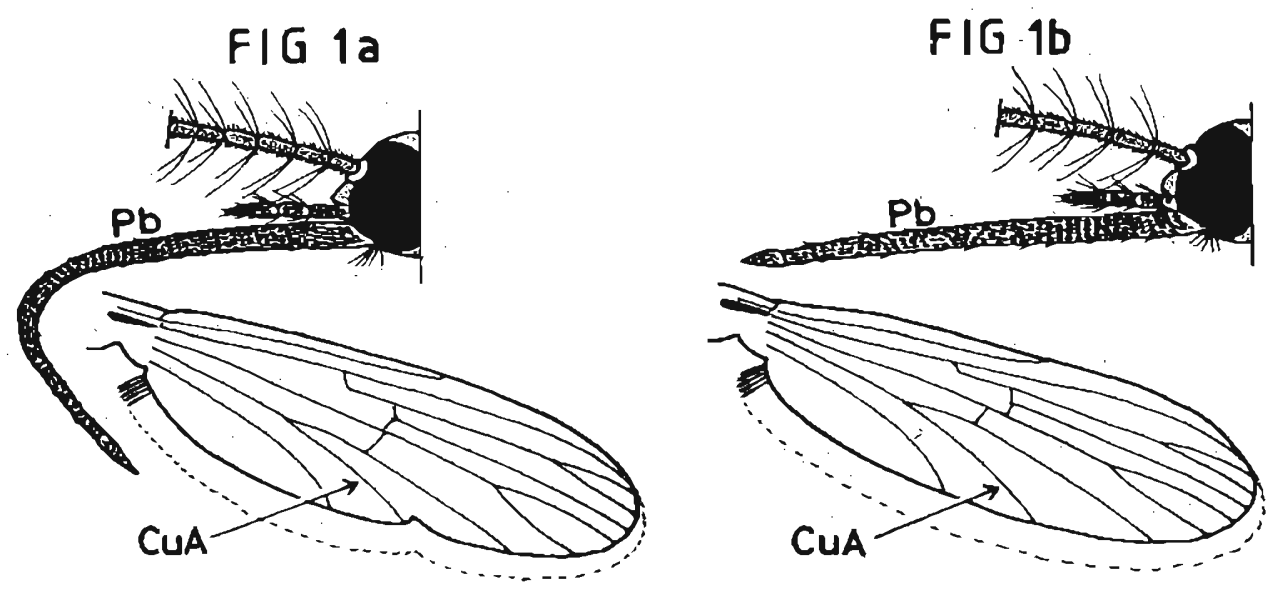

Figure 1a,b: Lateral views of proboscis shape, and dorsal views of posterior margin of wing showing presence or absence of indentation near terminus of veln CuA.

\section{FIG 2a}

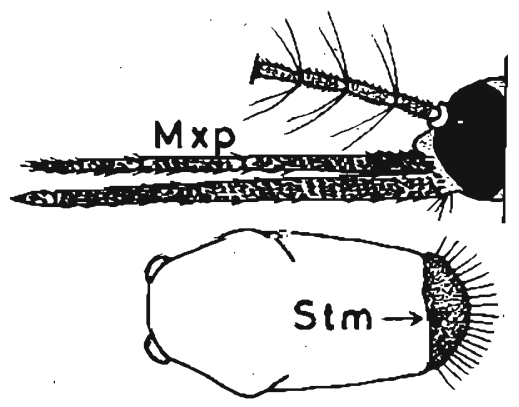

FIG 2b

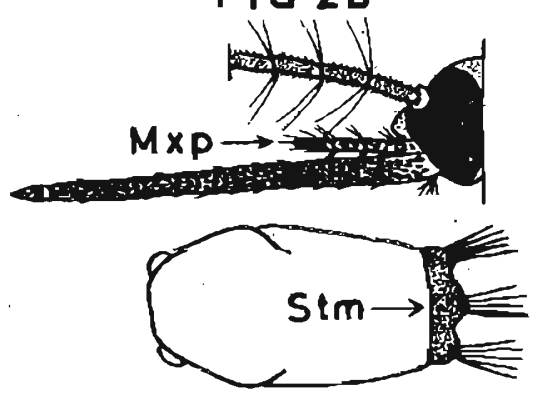

Figure 2a,b: Lateral views of relative lengths of maxillary palpi, and dorsal views of scutellum shape and setal distribution.

\section{FIG 33}

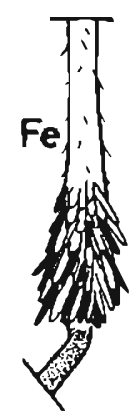

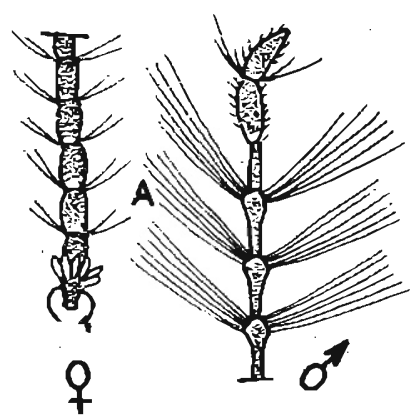

FIG 3b
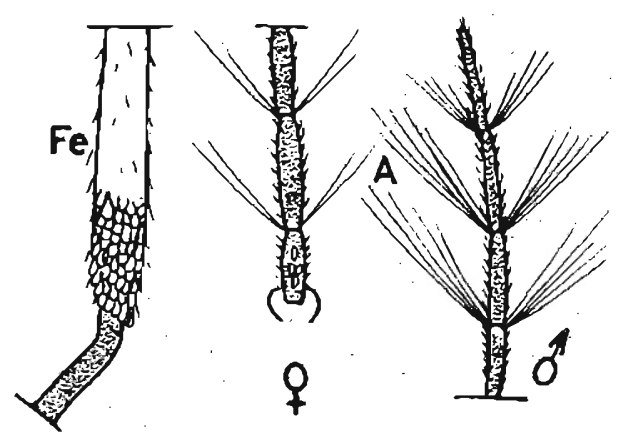

Figure 3a,b: Lateral views of scalation near tibiofemoral joint of hindfemur, and dorsal views of shape and scalation of male and female antennal flagellomeres. 


\section{FIG $4 a$}

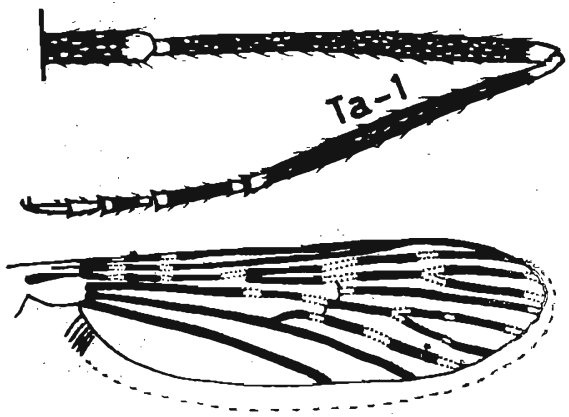

FIG $4 b$

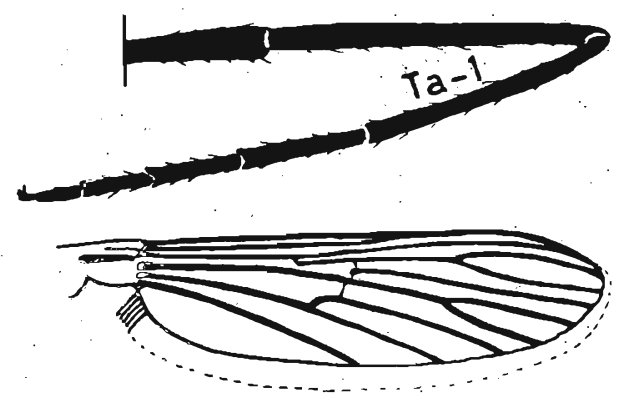

Figure 4a,b: Lateral views of midleg showing length of tarsomere-1 relative to tarsomeres 2-5, and dorsal views of wing with or without pale markings on veins.

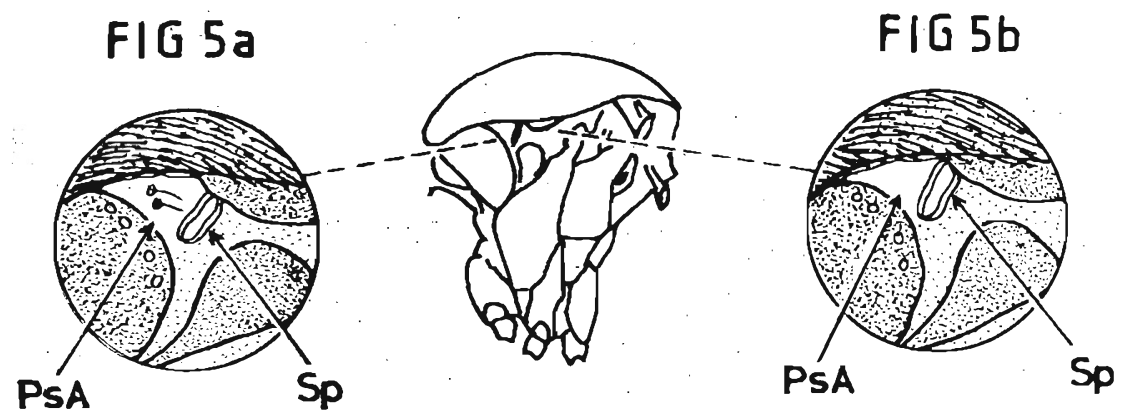

Figure 5a,b: Lateral views of thorax showing presence or absence of setae on prespiracular area.

FIG 6a

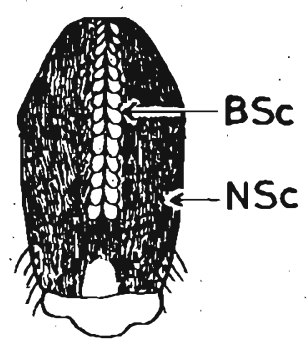

FIG 6b

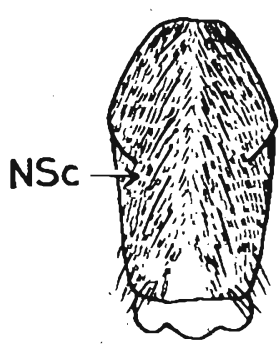

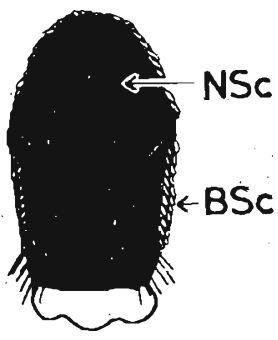

Figure 6a,b: Dorsal views of scutum showing different patterns of broad and narrow scalation. 
FIG 7a

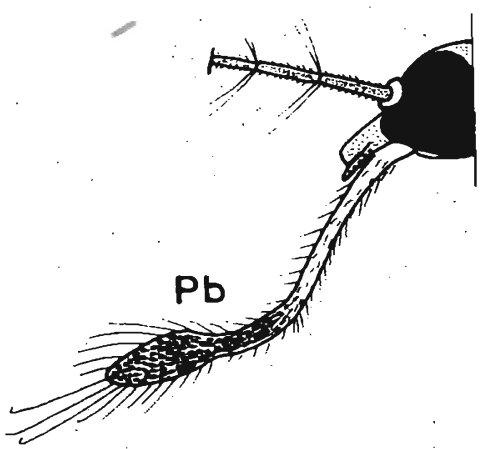

FIG 7b

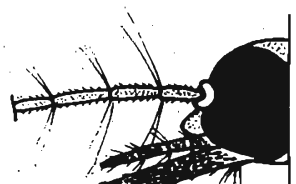

Figure 7a,b: Lateral views of densely setose, terminally swollen proboscis and normal proboscis.

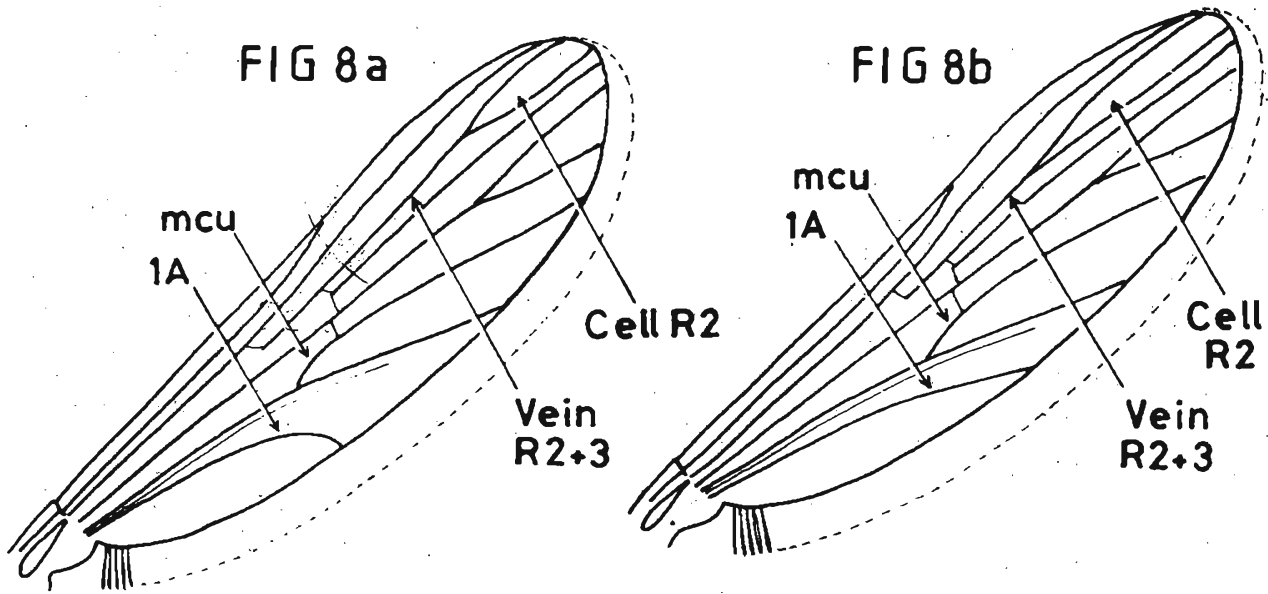

Figure 8a,b: Dorsal views of wing showing terminus of vein 1-A in relation to mcu.

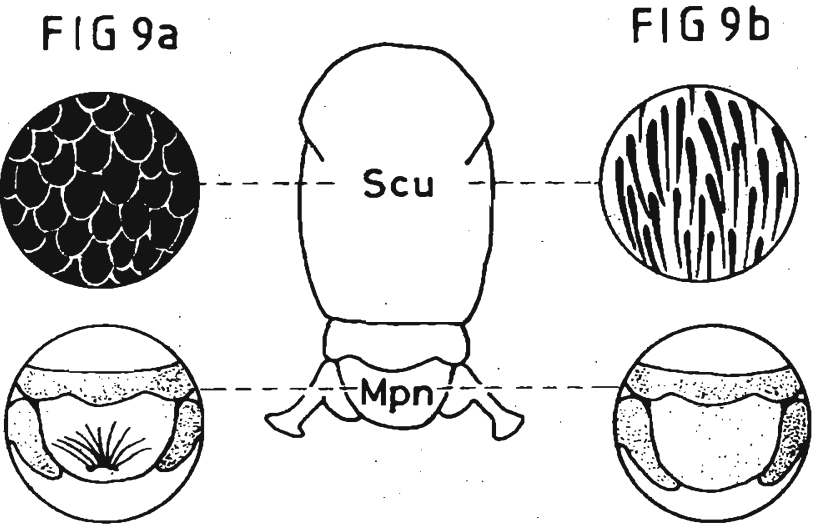

Figure 9a,b: Dorsal views of thorax showing scalation of scutum and presence or absence of setae on mesopostnotum. 

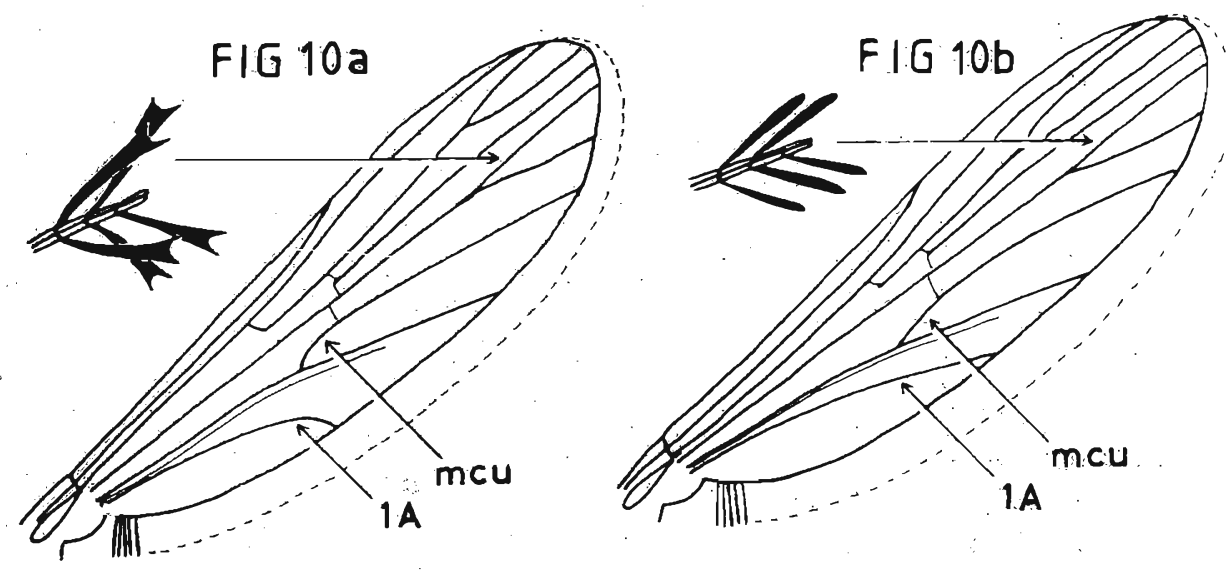

Figure 10a,b: Dorsal views of wing showing nature of outstanding scales and terminus of vein 1-A in relation to mcu.

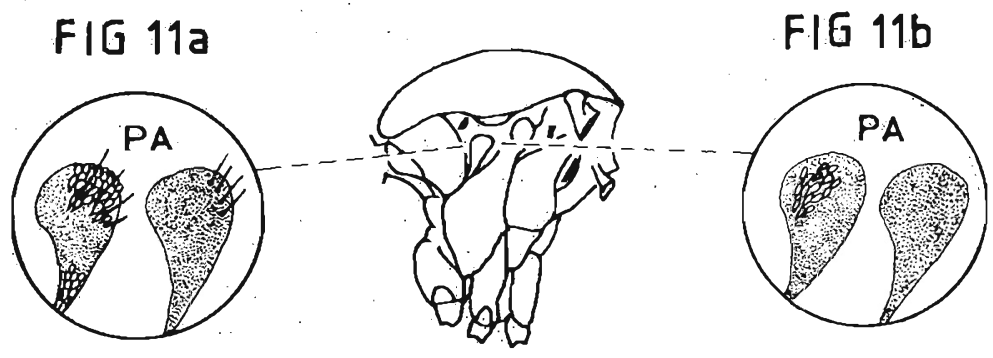

Figure 11a,b: Lateral views of thorax showing presence or absence of setae on postspiracular area.

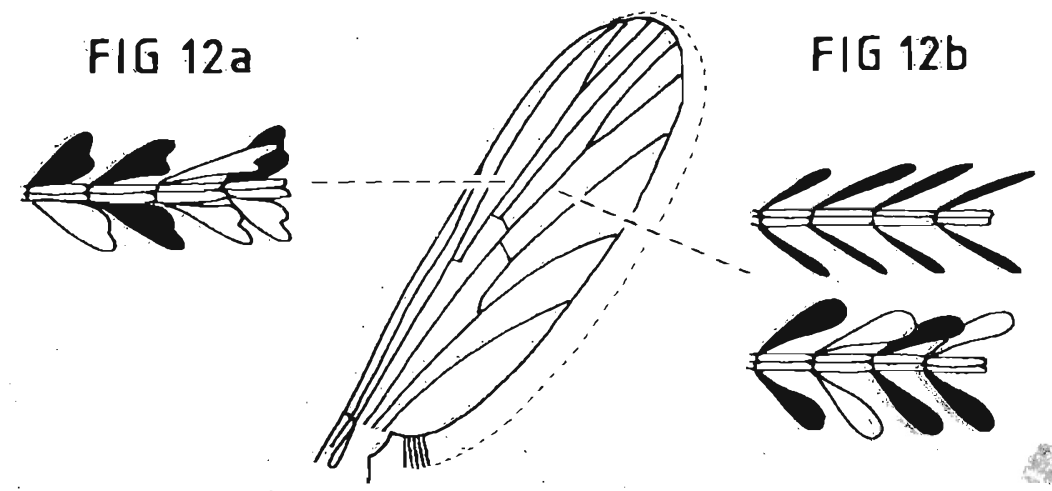

Figure 12a,b: Dorsal views of wing showing symmetry of broad and narrow scales. 
FIG $13 a$

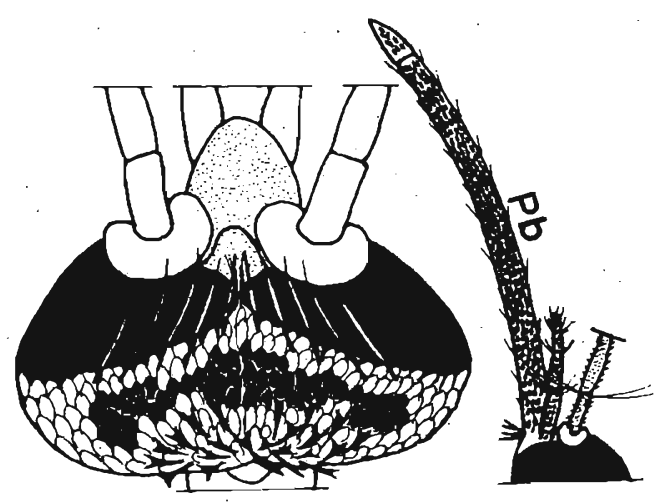

FIG 13b

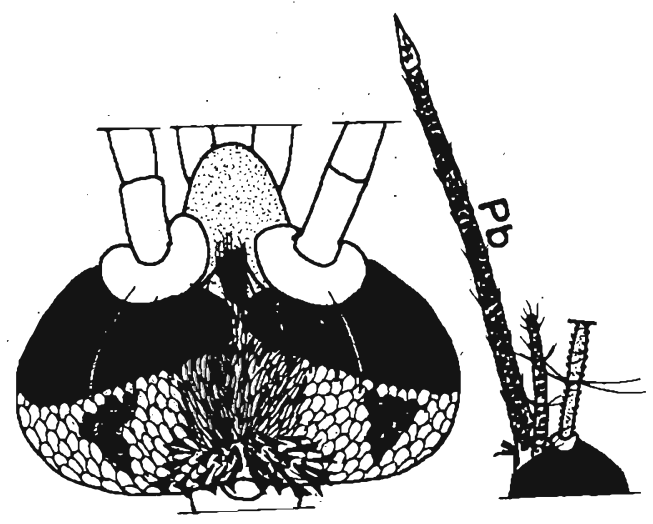

Figure 13a,b: Dorsal and lateral views of head showing decumbent scales on occiput, curvature of proboscis, respectively.

\section{FIG 14 a}
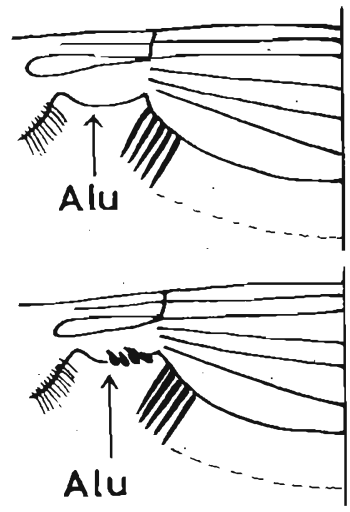

FIG $14 b$

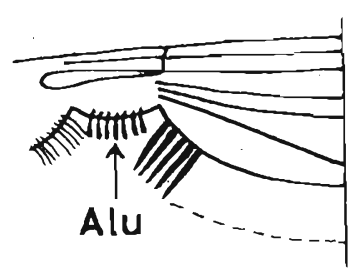

Figure 14a,b: Dorsal views of wing showing scalation on alula.

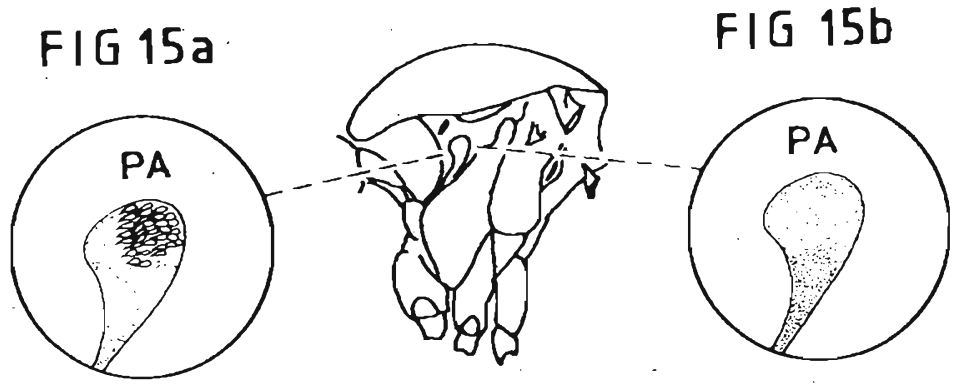

Figure 15a,b: Lateral views of thorax showing presence or absence of scales on postspiracular area. 


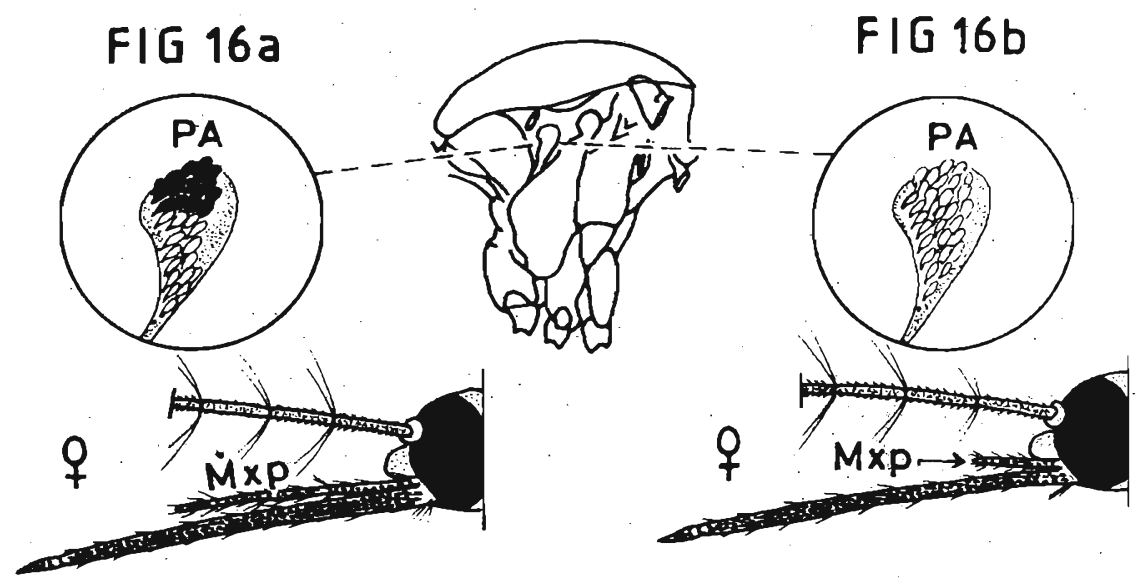

Figure 16a,b: Lateral views of thorax showing scalation of postspiracular area, and of head showing nature of maxillary palpus.

\section{FIG 17a}
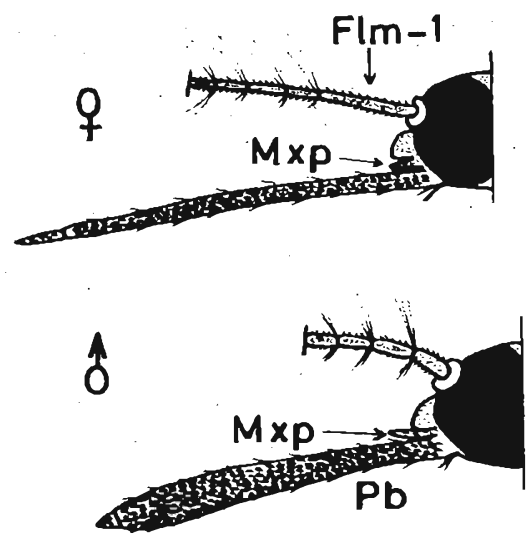

FIG 17b

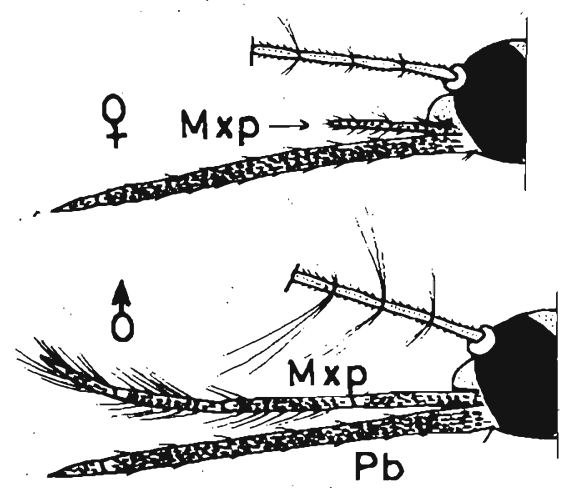

Figure 17a,b: Lateral views of head showing nature of male and female maxillary palpus.

FIG 18a

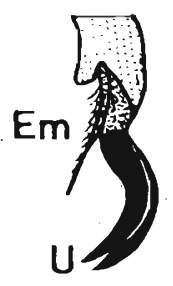

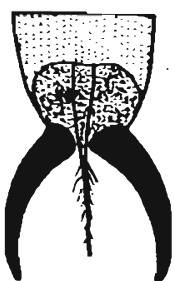

FIG 18b

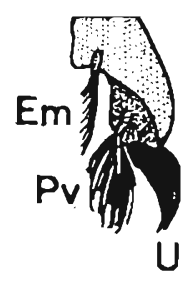

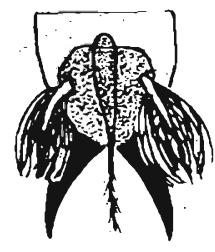

Figure 18a,b: Lateral and ventral views of hindleg showing empodium and pulvillus. 
FIG 19a

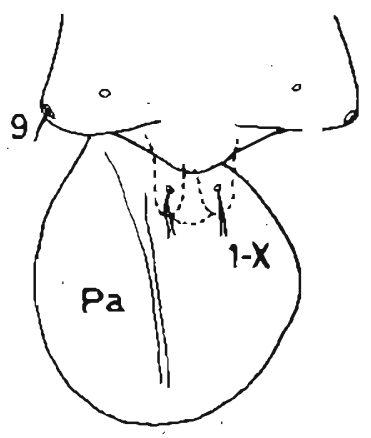

FIG 19b

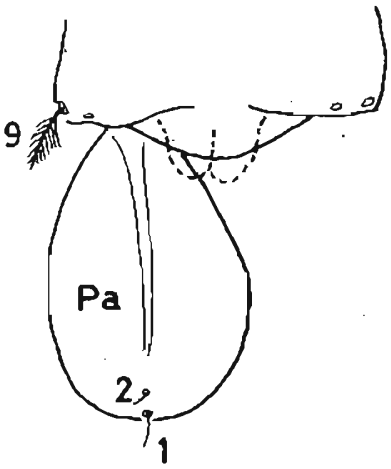

Figure 19a,b: Dorsal views of posterior end of pupal abdomen, showing presence or absence of seta $1 \cdot X$.
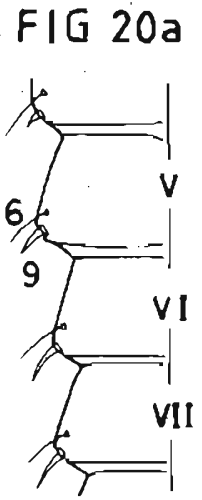

FIG 20b

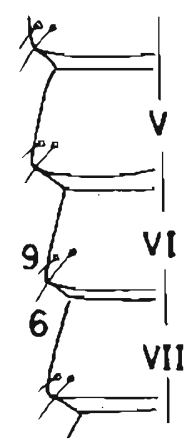

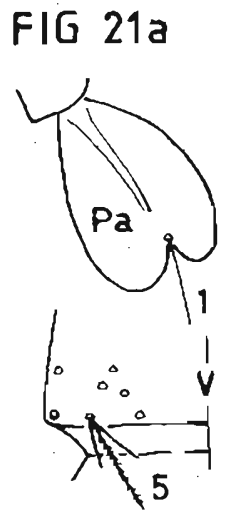

FIG 21b

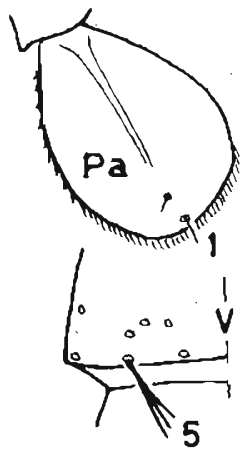

Figure 20a,b: Dorsal views of abdominal Figure 21a,b: Dorsal views of paddle showing setae 9-IV-VII. nature of margin and seta $1-P a$, and of abdominal segment $V$ showing nature of seta $5 \cdot V$.

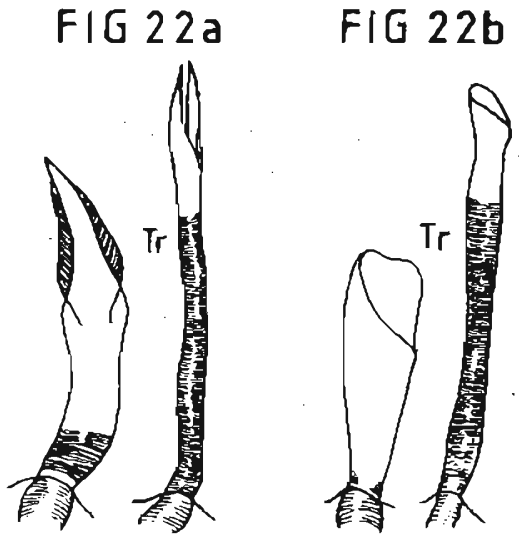

Figure 22a,b: Lateral views of rootpiercing and non-piercing trumpets.
FIG 23a

FIG 23b
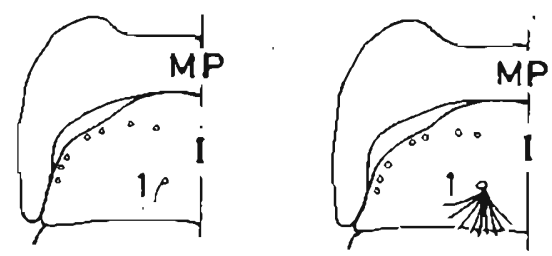

Figure 23a,b: Dorsal views of abdominal seta 1-I. 
FIG $24 a$

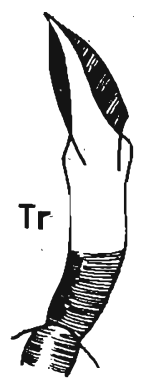

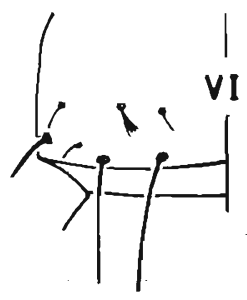

FIG 24b

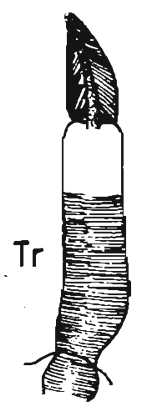

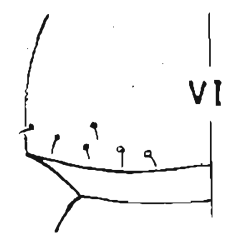

Figure 24a,b: Lateral views of root-piercing trumpets, and dorsal views of setal development on abdominal segment VI.

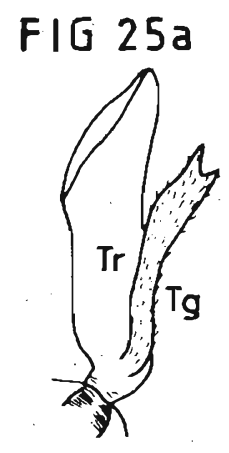

FIG 25b

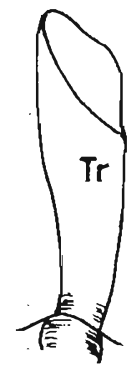

FIG $26 a$

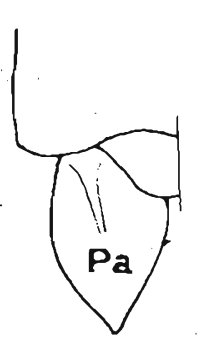

FIG 26b

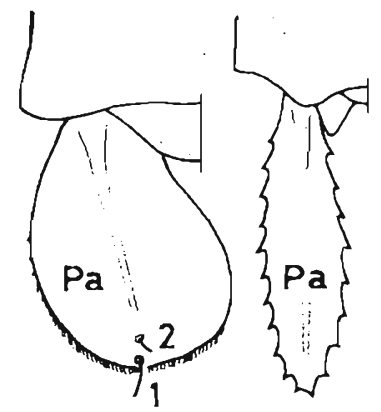

Figure 25a,b: Lateral views of trumpet with Figure 26a,b: Dorsal views of spiculation and without tragus. on paddle margin.

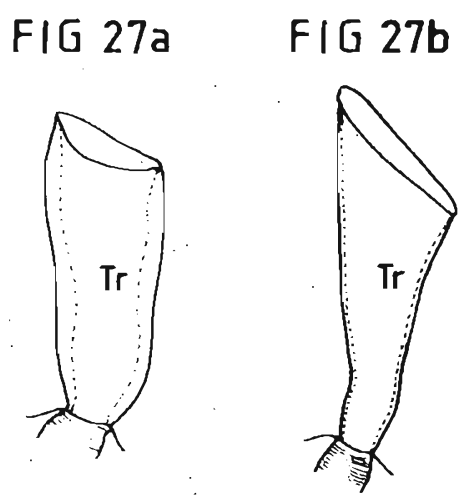

Figure 27a,b: Lateral views of trumpet showing separation of inner and outer walls.
FIG 28a

FIG 28b

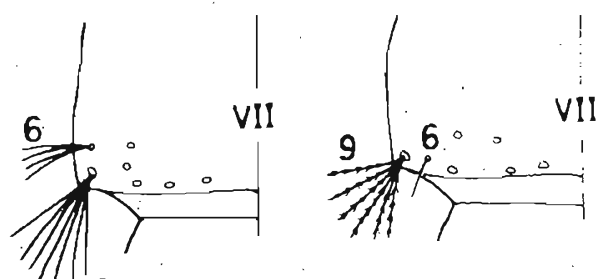

Figure 28a,b: Dorsal views of relative positions and development of abdominal setae $6,9-$ VII. 
FIG 29a

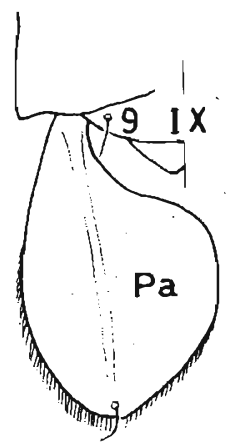

FIG 29b

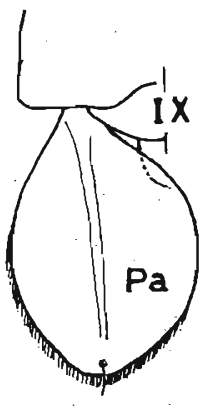

FIG 30a

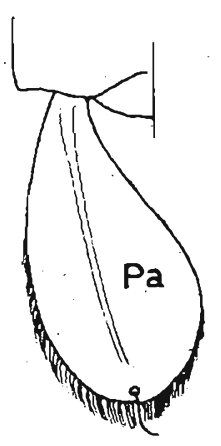

FIG 30b

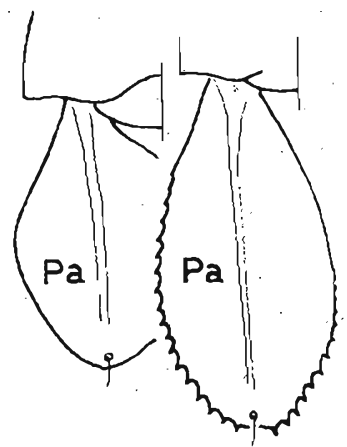

Figure 29a,b: Dorsal views of posterior end showing presence or absence of seta $9-I X$, and shape of inner margin of paddle.

FIG 31a

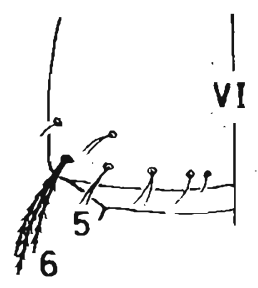

FIG 31b

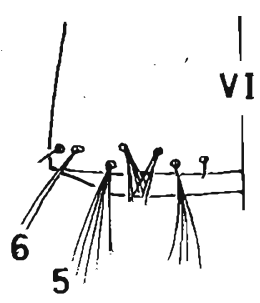

Figure 31a,b: Dorsal views of relative development of abdominal setae 5,6-VI.

\section{FIG 33a}
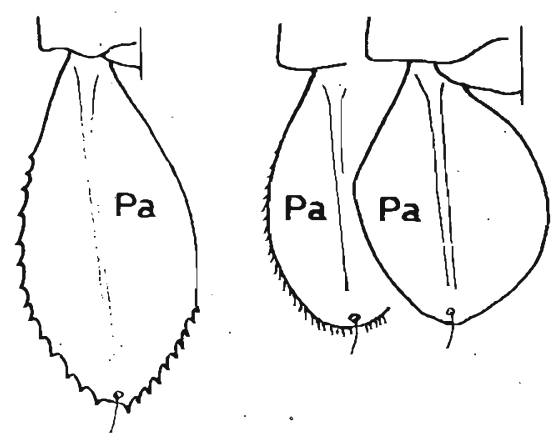

Figure 33a,b: Dorsal views of paddle showing spiculation of margin.
Figure 30a,b: Dorsal views of paddle showing spiculation of margin.

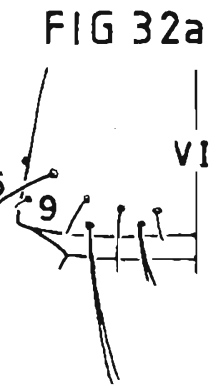

FIG 32b

Figure 32a,b: Dorsal views of abdominal seta $9-V I$ in relation to size of other setae on segment.

\section{FIG 34 a}

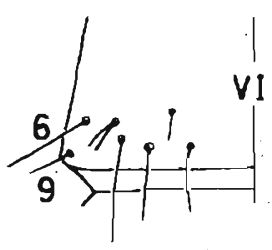

FIG 34b
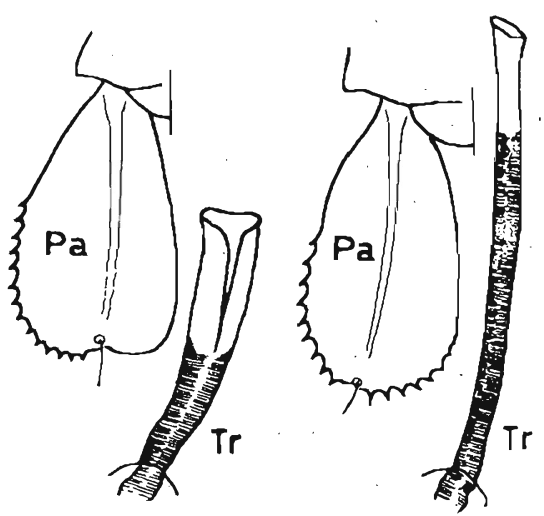

Figure 34a,b: Dorsal views of paddle showing spiculation of margin, and lateral views of trumpet showing relative length. 
FIG 35a

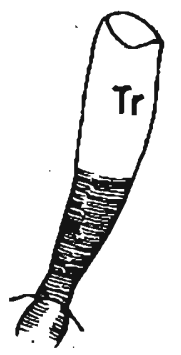

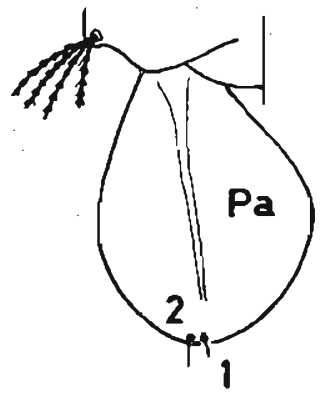

FIG 35b

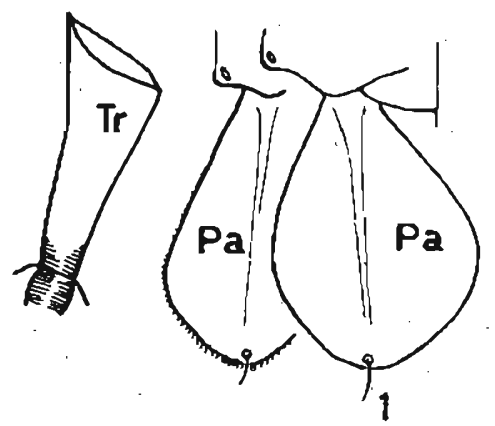

Figure 35a,b: Lateral views of subbasal tracheation on trumpet and dorsal views of paddle showing setae 1,2-Pa.

FIG 36a
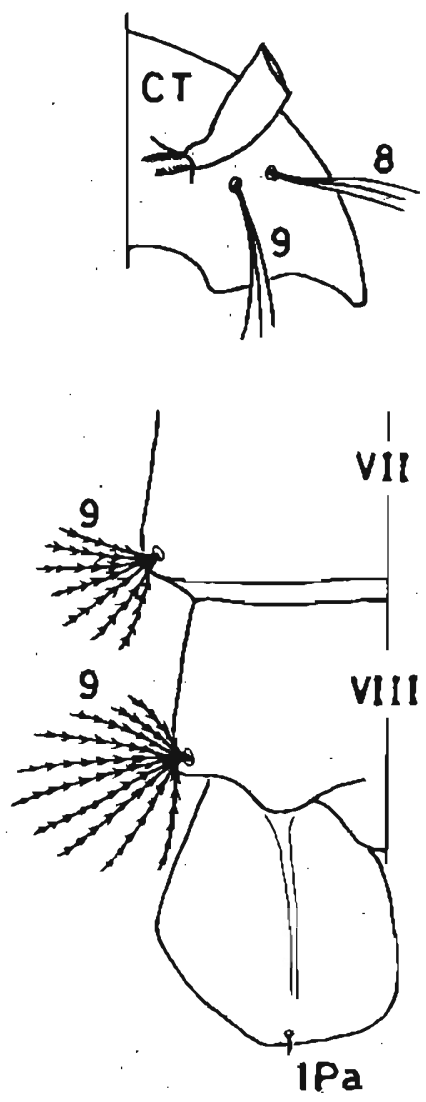

FIG 36b
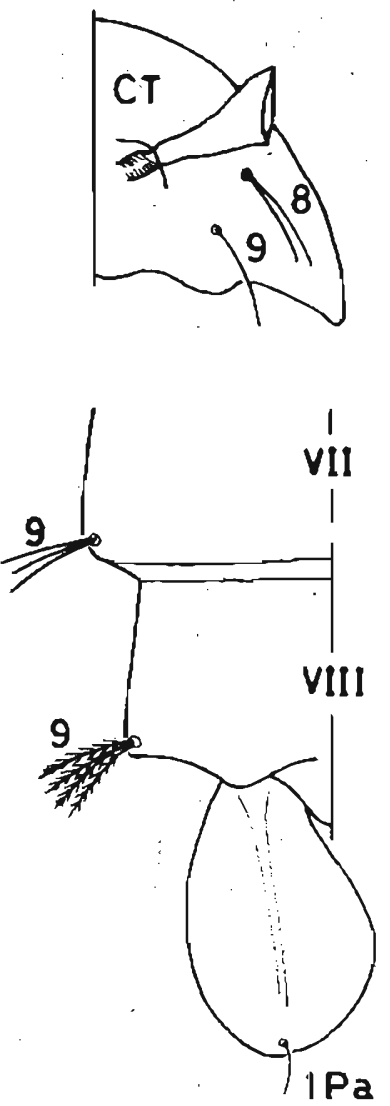

Figure 36a,b: Dorsal views of cephalothorax showing relative positions of setae 8,9-CT and dorsal views of abdominal setae 9-VII-VIII and paddle. 
FIG 37a

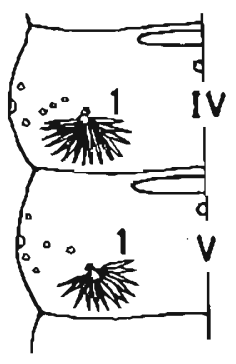

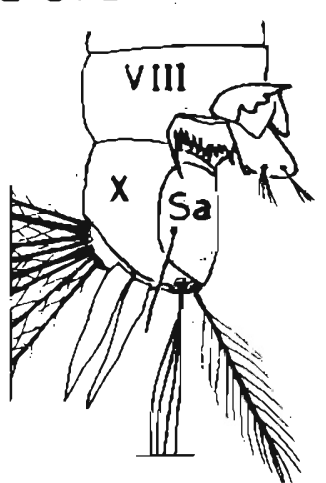

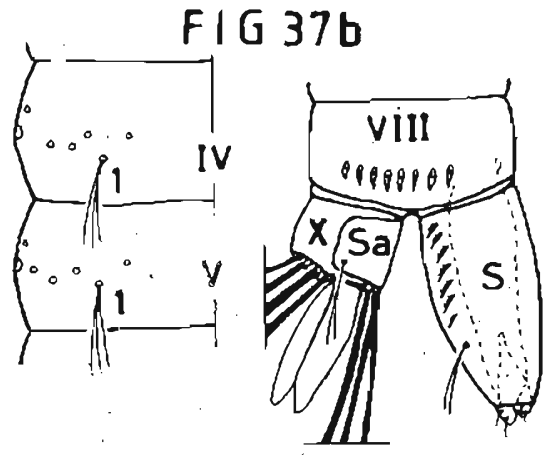

Figure 37a,b: Dorsal views of abdominal setae $1-I V-V$ and lateral views of posterior abdomen showing presence or absence of siphon.
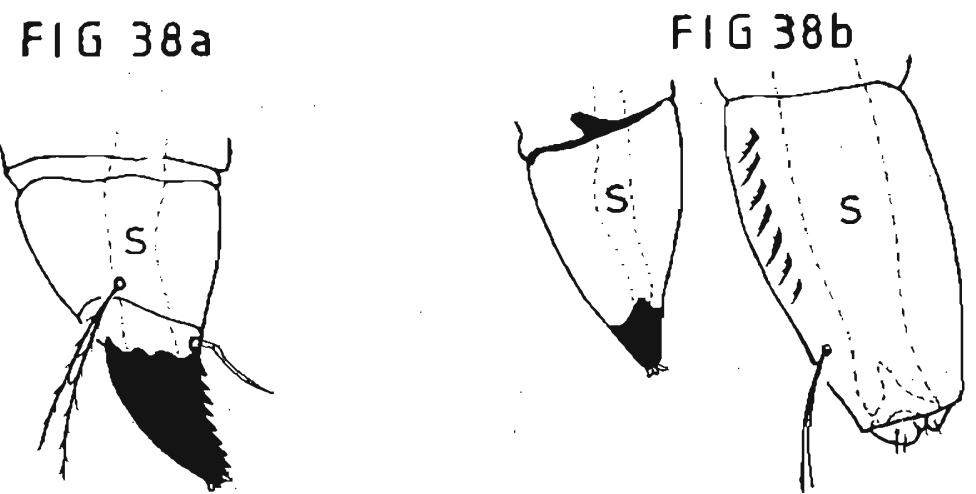

Figure 38a,b: Lateral views of saw-toothed and non-toothed siphons.

FIG 39 a

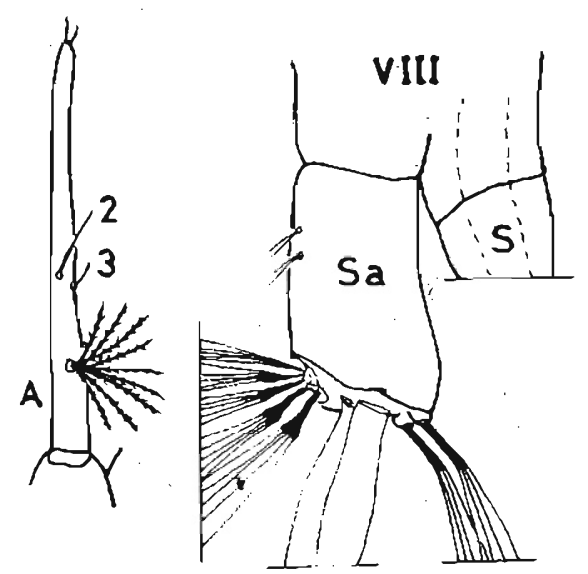

FIG $39 b$
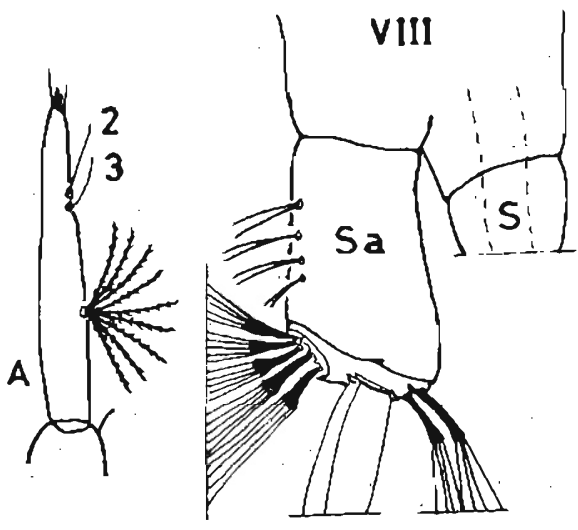

Figure 39a,b: Dorsal views of antenna showing positions of setae 2,3-A and lateral views of saddle setae. 
$F \| 40 a$

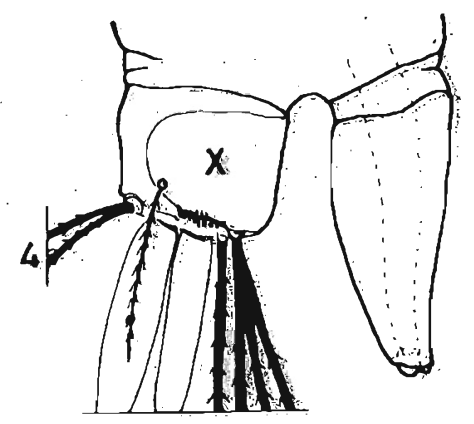

FIG 406

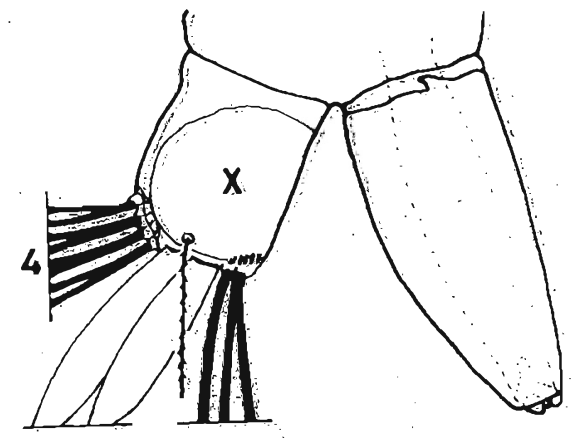

Figure 40a,b: Lateral views of ventral brush setae 4-X:

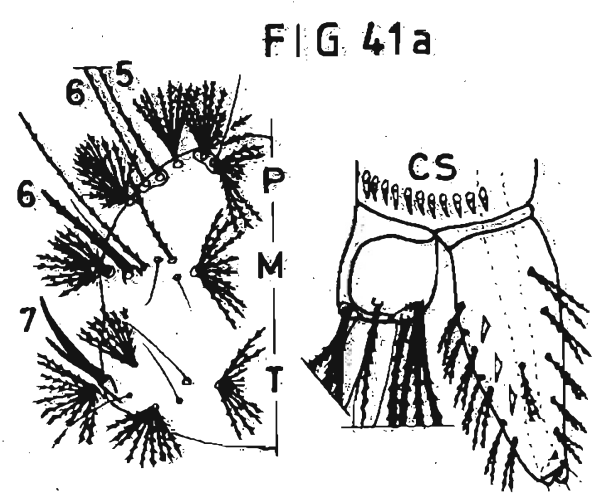

FIG $41 \mathrm{~b}$

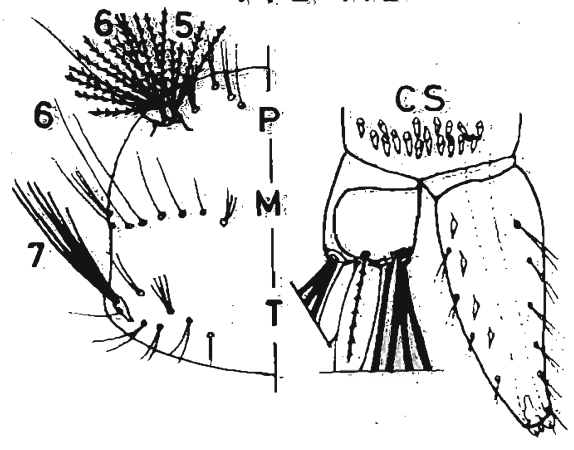

Figure 41a,b: Dorsal views of thoracic setae 5,6-P, 6 -M and 7 T andlateral views: of comb scale arrangement.

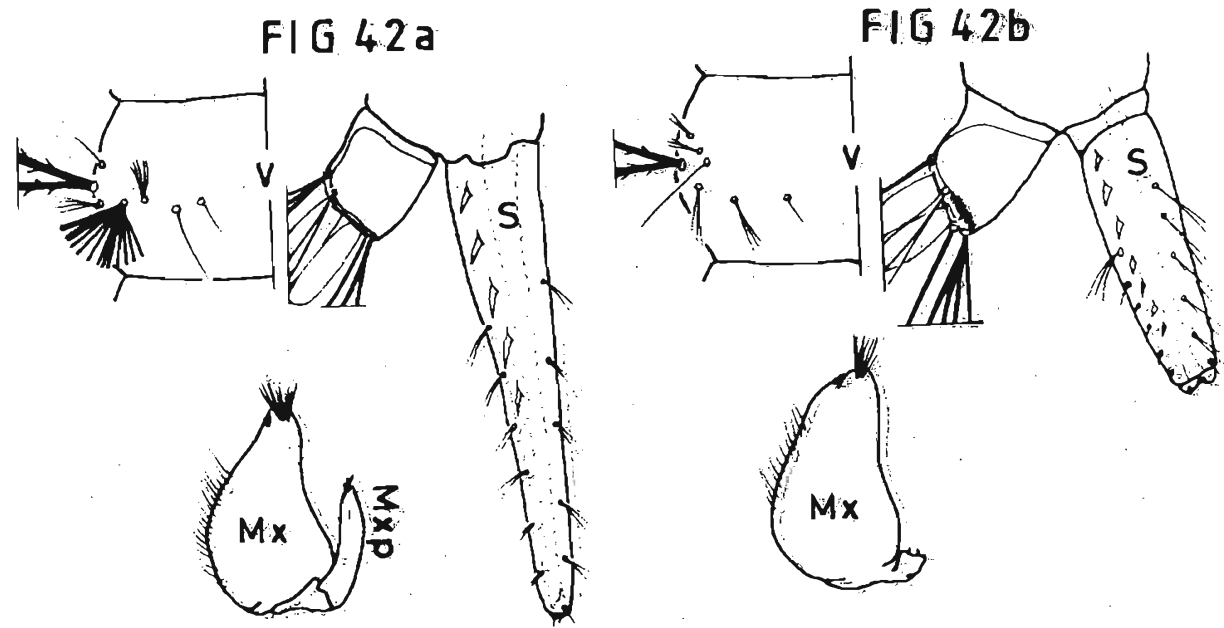

Figure 42a,b: Dorsal views of setae on abdominal segment $V$, lateral views of siphon; and ventral views of maxilla showing presence or absence of palpus. 


\section{FIG $43 a$}

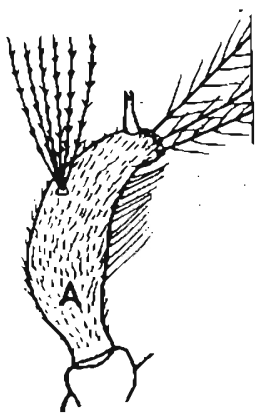

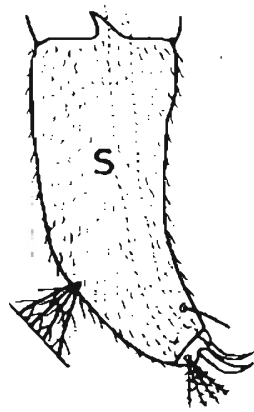

FIG $43 \mathrm{~b}$

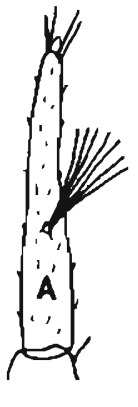

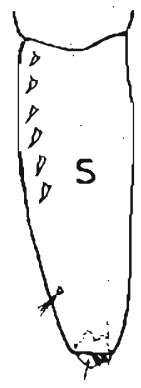

Figure 43a,b: Dorsal views of antenna and lateral views of siphon showing presence or absence of terminal paired hooks.

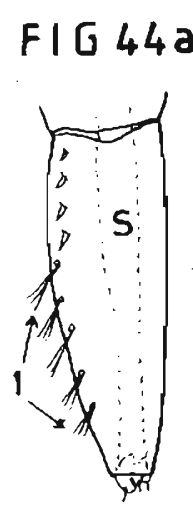

Figure 44a,b: Lateral views of the number of seta 1.5 on siphon.

\section{FIG $46 a$}
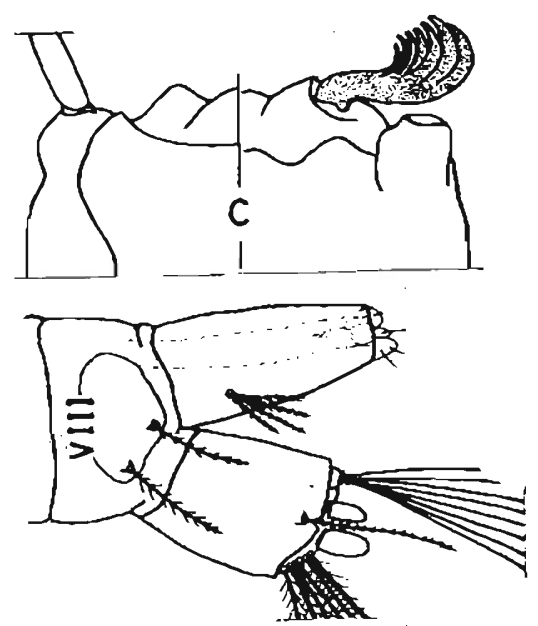

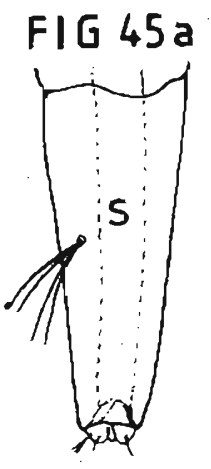

FIG 45b

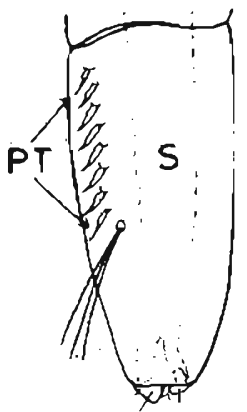

Figure 45a,b: Lateral views of siphon showing presence or absence of pecten.

FIG 46b
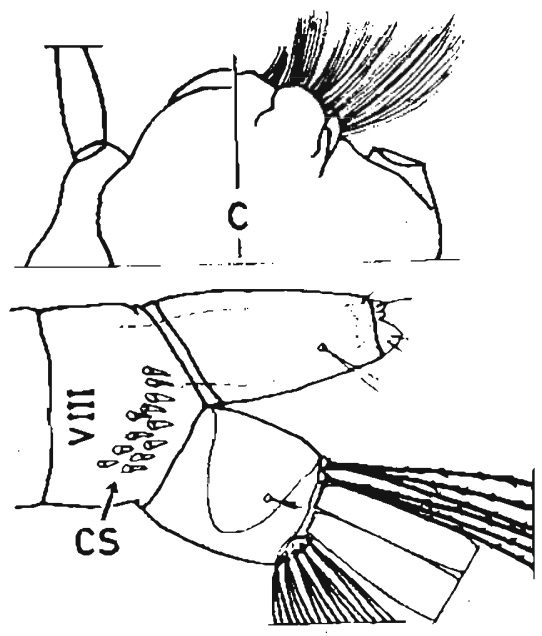

Figure 46a,b: Ventral views of palatal brush, and lateral views of abdominal segment VIII showing presence or absence of comb scales. 

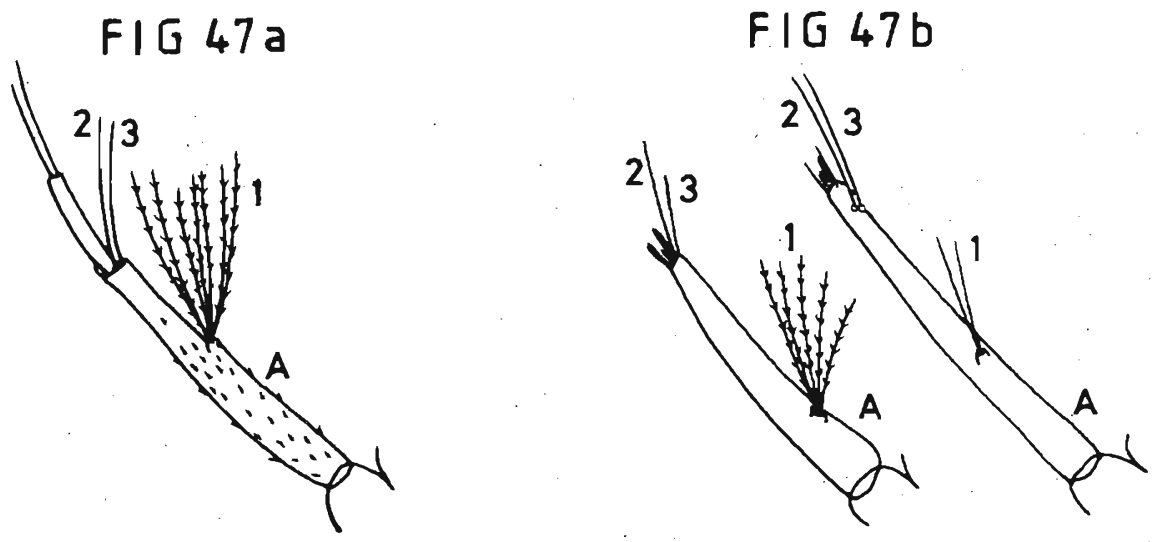

Figure 47a,b: Dorsal views of antenna showing presence or absence of joint, and points of attachment of setae 2,3-A.

FIG 48 a

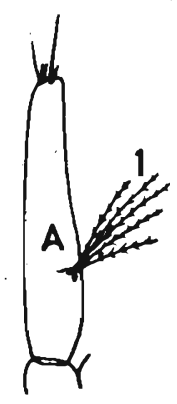

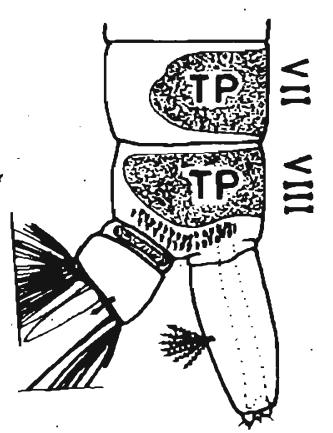

FIG $48 \mathrm{~b}$
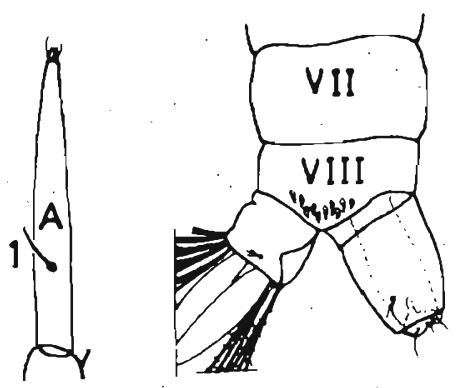

Figure 48a,b: Dorsal views of antennal seta 1 -A, and lateral views of abdominal segments VII and VIII showing presence or absence of tergal plates.
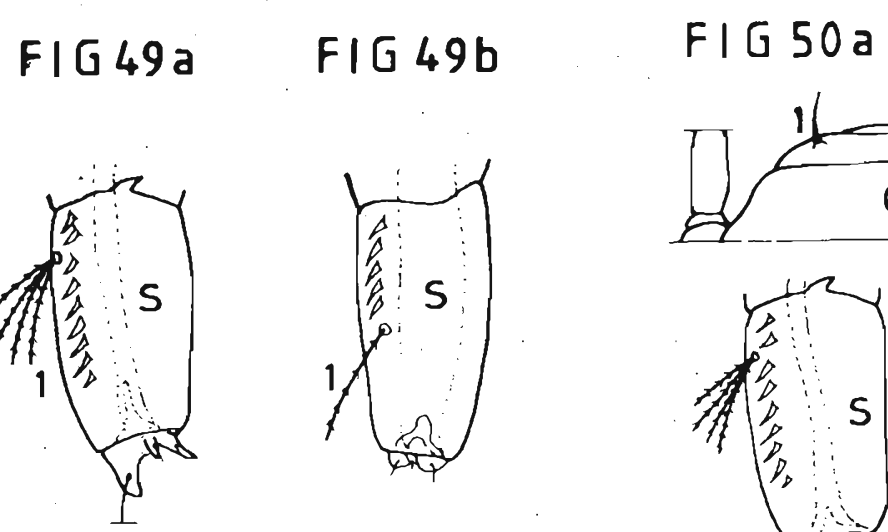

FIG $50 \mathrm{~b}$
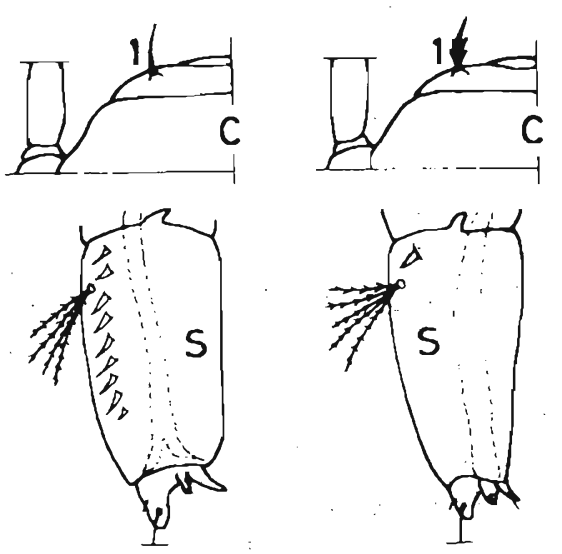

Figure 49a,b: Lateral views of siphon showing different points of attachment of seta 1-S.

Figure 50a,b: Dorsal views of head showing nature of seta 1-C, and lateral views of pecten teeth on siphon. 


\section{FIG 51 a}
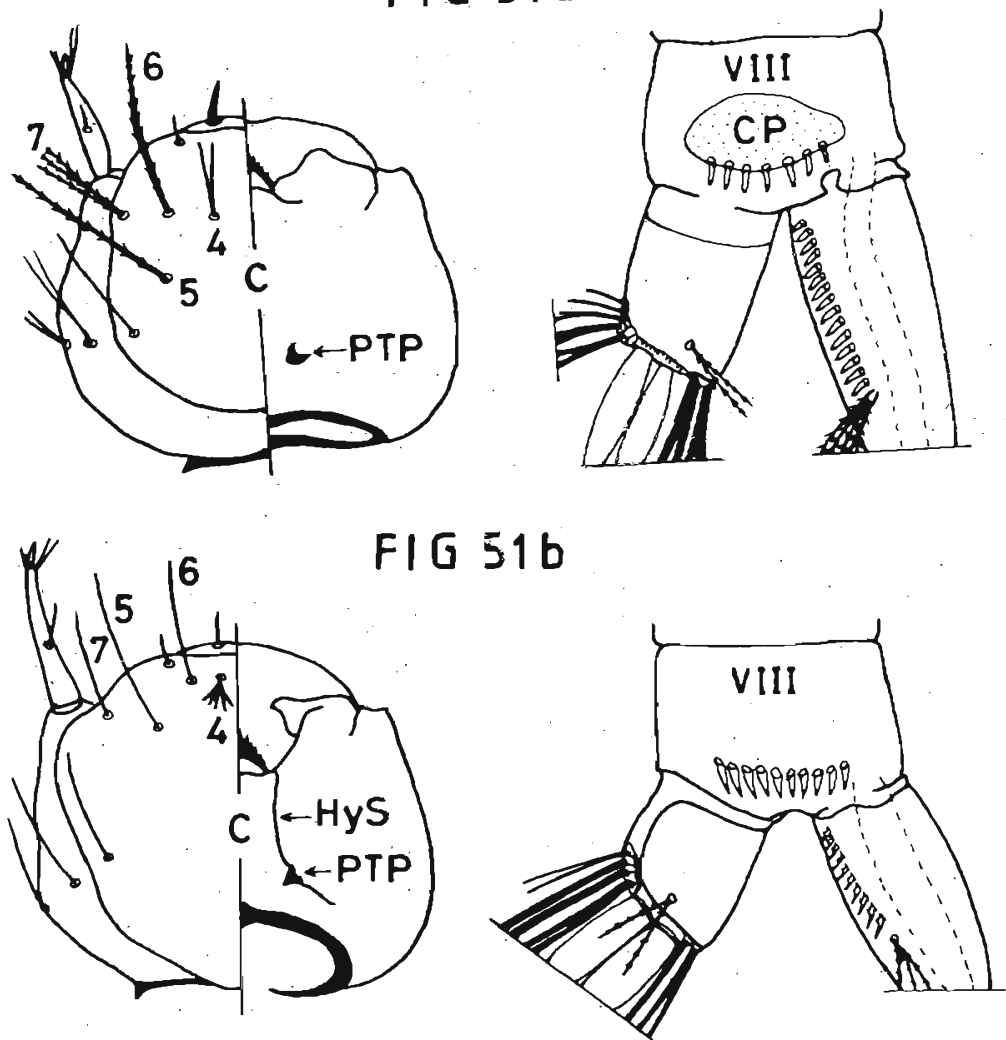

Figure 51a,b: Dorsal/ventral halves of head showing nature of seta $5,6-C$ and presence or absence of hypostomal suture respectively, and lateral views of abdominal segment VIII showing presence or absence of comb plate.

FIG 52 a

FIG 52b
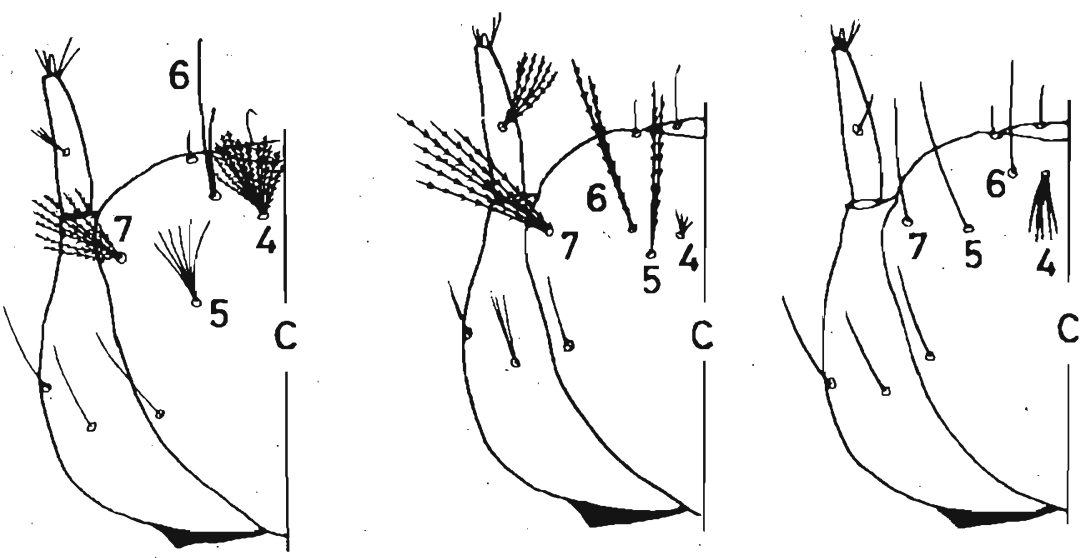

Figure 52a,b: Dorsal views of head showing nature and position of seta 4-C relative to $6,7-C$. 


\section{Acknowledgement}

I thank Dr. W.A. Samarawickrema for reviewing the draft manuscript, and for his encouragement of this work.

\section{References}

1. Amerasinghe F.P. (1991). A catalogue of the mosquitoes (Diptera: Culicidae) of Sri Lanka. Natural Resources Energy and Science. Authority of Sri Lanka, Colombo. 23 pp.

2. Amerasinghe F.P. (1993). A new species of Heizmannid from Sri Lanka. Mosquito Systematics 25: 110-115.

3. Peiris J.S.M., Amerasinghe P.H., Amerasinghe F.P., Calisher C.H., Perera L.P., Arunagiri C.K, Munasingha N.B. \& Karunaratne S.H.P.P. (1994). Viruses isolated from mosquitoes collected in Sri Lanka. American Journal of Tropical Medicine \& Hygiene 51(2): 154-161.

4. Carter H.F. (1924). The anopheline mosquitoes of Ceylon. 1. The differential characters of the adults and larvae. Ceylon Journal of Science (D) 1: 57-95.

5. Carter H.F. (1950). The genus Taeniorhynchus Lynch Arribalzaga (Diptera: Culicidae) with special reference to species occurring in Ceylon. Ceylon Journal of Science (B) 24: 1-26.

6. Senior-White R. (1927). Notes on Ceylon mosquitoes. II. The larvae of the commoner non-anopheline mosquitoes. Spolia Zeylanica 14: 61 -76.

7. Carter H.F. \& Wijesundara D.P. (1948). Notes on some Ceylon culicine mosquitoes. Ceylon Journal of Science (B) 23: 135-151.

8. Edwards F.V. (1922), A synopsis of adult oriental culicine (including megarhinine and sabethine) mosquitoes. Part 1. Indian Journal of Medical Research 10: 249-293.

9. Christophers S.R. (1933). The Fauna of British India, including Ceylon and Burma. Diptera Vol. IV. Family Culicidae. Tribe Anophelini. Taylor \& Francis, London. pp. 371.

10. Barraud P.J. (1934). The Fauna of British India, including Ceylon and Burma. Diptera Vol. V. Family Culicidae. Tribes Megarhinini and Culicini. Taylor \& Francis, London. 463 pp.

11. Thurman E.H.B. (1959). A contribution to a revision of the Culicidae of northern Thailand. Bulletin A-100, University of Maryland Agriculturai Experimental Station. $186 \mathrm{pp}$. 
12. Reid J.A. (1968). Anopheline mosquitoes of Malaya and Borneo. Studies from the Institute for Medical Research Malaysia. Government of Malaysia. No.31. 903 pp.

13. Amerasinghe F.P. (1990). A guide to the identification of the anopheline mosquitoes (Diptera : Culicidae) of Sri Lanka. I. Adult females. Ceylon Journal of Science (Biological Science) 21: 1-16.

14. Amerasinghe F.P. (1992). A guide to the identification of the anopheline mosquitoes (Diptera : Culicidae) of Sri Lanka. II. Larvae. Ceylon Journal of Science (Biological Science) 22: 1-13.

15. Amerasinghe F.P. A guide to the identification of the anopheline mosquitoes (Diptera : Culicidae) of Sri Lanka. III. Pupae. Journal of the National Science; Council of Sri Lanka 23(3): 115-129.

16. Jayasekera N. \& Chelliah R.V. (1981). An annotated checklist of mosquitoes of Sri Lanka. 16 pp. MAB Publication No. 8. National Science Council of Sri Lanka, Colombo.

17. Mattingly P.F. (1971). Contributions to the mosquito fauna of Southeast Asia. XII. Illustrated keys to the genera of mosquitoes (Diptera: Culicidae). Contributions of the American Entomological Institute 7(4): 1-84.

18. Rattanarithikul R. (1982). A guide to the genera of mosquitoes (Diptera: Culicidae) of Thailand with illustrated keys, biological notes and preservation and mounting techniques. Mosquito Systematics 14: 139-208.

19. Darsie R.F. \& Pradhan S.P. (1990). The mosquitoes of Nepal: their identification, distribution and biology. Mosquito Systematics 22: 69-130.

20. Reuben R., Tewari S.C., Hiriyan J. \& Akiyama J. (1994). Illustrated keys to species of Culex (Culex) associated with Japanese encephalitis in southeast Asia (Diptera: Culicidae). Mosquito Systematics 26: 75-96.

21. Harbach R.E. \& Knight K.L. (1980). Taxonomists' glossary of mosquito anatomy. Plexus Publishing Inc., New Jersey. 415 pp. 